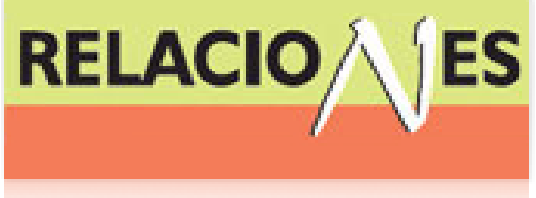

Relaciones. Estudios de historia y sociedad ISSN: 0185-3929

relacion@colmich.edu.mx

El Colegio de Michoacán, A.C

México

Velázquez, Pedro A.

Los caminos hacia el conocimiento. Los diarios personales del Ing. Agustín M. Chávez

Relaciones. Estudios de historia y sociedad, vol. XXXIII, núm. 132, 2012, pp. 223-269

El Colegio de Michoacán, A.C

Zamora, México

Disponible en: http://www.redalyc.org/articulo.oa?id=13725134007

Cómo citar el artículo

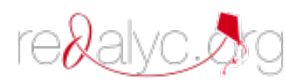

- Número completo

- Más información del artículo

Página de la revista en redalyc.org

Sistema de Información Científica

Red de Revistas Científicas de América Latina, el Caribe, España y Portugal Proyecto académico sin fines de lucro, desarrollado bajo la iniciativa de acceso abierto 


\title{
Los caminos hacia el conocimiento. Los diarios personales del Ing. Agustín M. Chávez
}

\author{
Pedro A. Velázquez*
}

UMSNH/ INAH-MICHOACÁN

El diario personal está más asociado al uso femenino por su característica íntima y refugio de libertad de expresión socialmente negada; en algunos hombres se podrían encontrar referencias similares, sin embargo, estuvo más vinculado a documento de apoyo con lo que cambia su sentido a "cuadernillo" de trabajo. En ese sentido los diarios personales de Bronislaw Malinowski son un buen ejemplo. El Ing. Agustín M. Chávez da un nuevo sentido y enfoque al utilizar los diarios personales, tanto para sus asuntos de carácter personal, como de trabajo, valorado a través de un criterio estadístico, en un estricto contexto ético autodeterminado y el desarrollo personal de un complicado sistema simbólico que le ayudaba a representar esas tres condiciones. Dicho "Método de vida" como él mismo le llamó a la postre, le permitió sistematizar no nada más sus descubrimientos, sino también su pensamiento y hasta su conducta personal. Las fuentes documentales provienen de sus archivos particulares: misivas y los propios diarios que abarcan una periodicidad de 1872 a 1902.

(Ciencia, inventor, positivismo, método de vida, diarios personales)

INTRODUCCIÓN

mbuido por los avances sociológicos y filosóficos de la época, así como a la estricta disciplina que se autoimpuso, Chávez consideró pertinente sistematizar no sólo sus descubrimientos, sino también su razonamiento y hasta su conducta personal. Esto le llevaría a buscar un procedimiento escrito que le auxiliara en lograr dichos objetivos.

*antropvelazquez@gmail.com 


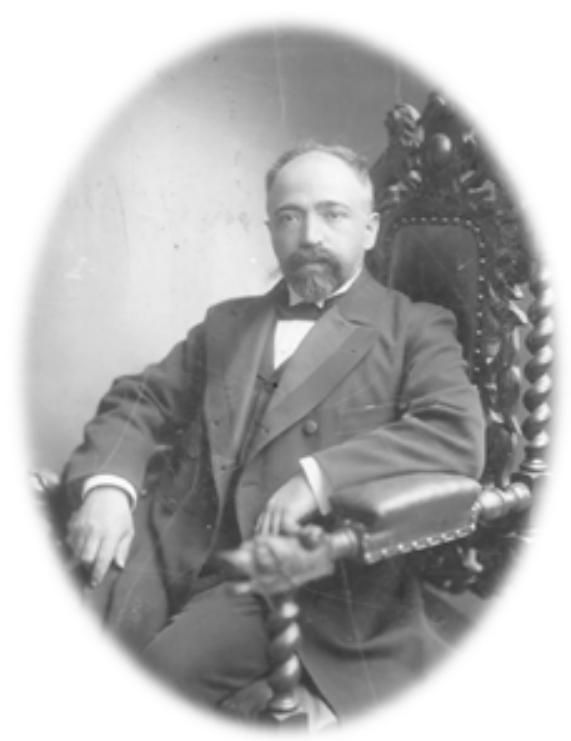

Foto 1. A. M. Chávez, c. 1895.

Tras décadas de perfeccionamiento empírico, logró desarrollar todo una serie de reglas que he denominado "Método de vida" ya que este proceder contó con varios de los criterios propios del método científico, tales como: observación, detección del problema, objetivos, experimentación (aplicación), medición y su evaluación respectiva; con la idea de ir perfeccionando una serie de reglas para regir su conducta.

El desarrollo, aplicabilidad y evaluación del mismo, quedó registrado por día, semana, mes y año en cuadernillos a modo de diarios personales que traía consigo donde, además, anotaba planes y pendientes. La simple revisión de ellos es todo un deleite por la belleza en la caligrafía, los colores, el diseño y el manejo de conceptos.

En este ensayo se presenta, por vez primera, un análisis de una pequeńa parte documental del extenso archivo particular de Agustín Manuel Chávez Pedroza. Esta visión parcial de sus diarios que, más que un "Manual de Buenas Costumbres", de cuño corriente para la época, son todo un Método de Vida; que nos permite aproximarnos al entendimiento de la personalidad del inventor $y$, a su vez, es un atisbo a cómo entendía el mundo. 
¿Quién fue Agustín M. Chávez? ¿Por qué hoy se sabe muy poco de su trayectoria científica y su contribución a la construcción del México moderno?

El Ing. Agustín M. Chávez no sólo era un positivo ${ }^{1}$, sino un optimista del beneficio que traería la ciencia a la humanidad; en este sentido compartía -como hombre universal de su época- esa creencia incuestionable, que la humanidad estaba llamada a la felicidad plena en todos los sentidos.

Chávez fue contemporáneo de la segunda revolución industrial ${ }^{2}$ pero, como muchos hombres y mujeres de su época, fue testigo y logró comprender las contradicciones entre ese optimismo pletórico y las condiciones sociales de las mayorías en aquel México con pobreza hiriente.

De igual manera confrontó al imperialismo europeo con sus nacionalismos desbordados que imponían sobre el resto de las naciones condiciones ventajosas para los primeros. Esas discordancias fueron semillas para las reivindicaciones sociales y laborales que viviría el siglo veinte. Con todo, Chávez buscó el fomento al derecho social de los mexicanos en la participación y repartición de la riqueza, la educación gratuita, laica al servicio de la ciencia y la técnica para que todos vivieran mejor.

La figura del Ing. Chávez es atípica, si bien es contemporáneo del periodo que se conoce como "Porfiriato"” lo real es que su pen-

${ }^{1}$ En el sentido filosófico del término, el cual afirmaba que el único conocimiento auténtico es el conocimiento científico, y que tal conocimiento solamente puede surgir de la afirmación positiva de las teorías a través del método científico.

${ }^{2}$ Se sitúa habitualmente entre los años 1870 y 1914 y se caracteriza por el desarrollo de las industrias química, eléctrica, del petróleo y del acero. Otros desarrollos significativos de este periodo incluyen la introducción del motor de combustión interna, el desarrollo del aeroplano, la comercialización del automóvil, la producción en masa de bienes de consumo, la refrigeración mecánica y la invención del teléfono.

${ }^{3}$ El Porfiriato se define por varios criterios, el primero y más común es relativo al cronológico, que va de 1876 con la sucesión a la presidencia de Sebastián Lerdo de Tejada, hasta 1911 con la renuncia del general Díaz; otro criterio analítico -por demás interesante- es a partir del quehacer de las estructuras de poder que el propio régimen dio cabida y que, por su heterogeneidad, se pueden etiquetar como: "elites liberales", "científicos", "positivistas", pero también "anarquistas" y "antirreeleccionistas". François-Xavier Guerra, México: del antiguo régimen a la Revolución, secc. Obras de Historia, tomo II, 6a Reimp., México, FCE, 2003, 330 y ss. 
samiento y acción lo ubica en una posición singular. De acuerdo a la categorización de Guerra ${ }^{4}$ estaría más cercano a lo que él identifica como "sociedades de pensamiento" cuyo fin era "pensar (y) elaborar la opinión"; 5 estas sociedades se caracterizaban por su libre adhesión al pequeño resquicio de las estructuras modernas que en el México de fines del XIX se intentaban consolidar.

Es atípica porque Chávez se mantuvo ideológicamente hablando al margen de las estructuras del poder, no formó parte del grupo de los "científicos", ${ }^{6}$ ni lo podemos situar como un intelectual (positivista) fiel o servidor al régimen.

Si bien se desempeñó en diversos cargos del ámbito federal, fue más circunstancial, orillado por su precaria condición económica y a sus expectativas de encontrar aplicabilidad de sus conocimientos teóricos en soluciones útiles para la patria. ${ }^{7}$ El siguiente extracto de una misiva personal a su esposa, nos permite afirmarlo al apuntar: "Tu bien sabes por lo que hemos hablado, te he escrito y me conoces, que yo, si hemos de llegar á tener un porvenir, no ha de ser mas que por el lado de los proyectos pues en caso de ser yo lego es, creo, para eso únicamente. De empleado no sirvo, ni me gusta, ni es eso porvenir: seré empleado si no me queda otro recurso [...]"8

El Ing. Agustín M, Chávez fue un científico nato; en su haber podemos contabilizar más de veinte inventos diversos, desarrollados

${ }^{4}$ Op. cit., p. 332.

${ }^{5}$ Ibid., p. 331.

${ }^{6} \mathrm{Al}$ respecto, Luis Cabrera señala en su obra "Dos opiniones sobre los científicos", que en realidad no había un grupo como tal, acaso un "modo presuntuosamente petulante, un grupo de personas que tenían la pretensión de guiarse por los dictados de la ciencia en la resolución de nuestros problemas nacionales" Historia de México, México, Salvat, tomo 8, 1974, 255 y ss. Por su parte Guerra los categoriza como un grupo de jóvenes intelectuales, positivistas liberales "ya sean porfiristas o anti porfiristas, [...] sin poder real en el régimen; es un grupo de amigos de la misma generación y no un grupo político. En este grupo, algunos jóvenes intelectuales se convierten de hecho en el braintrust [...]. A ellos se les confían los estudios, los informes, los dictámenes periciales, las plazas en las comisiones técnicas" Guerra, op. cit., 82 y 83 .

${ }^{7}$ En su archivo epistolar existen un número considerable de documentos donde está plasmado ese ferviente nacionalismo o amor a la Patria. Cfr. capítulo Iv, "Amor, Ciencia y Gloria” en Pedro A. Velázquez, Amor, ciencia y gloria. La contribución de los Chávez y los Castañeda en el desarrollo del México moderno, Zamora, El Colegio de Michoacán, 2001.

${ }^{8}$ Velázquez, op. cit., 204. 
sobre la idea de su aplicación en la agricultura, la mecánica, la química, la navegación marítima y aérea. Varios de ellos premiados en Europa y los Estados Unidos, otros patentados y muchos forzados al olvido por la falta de financiamiento para probarlos y construirlos. Además de éstos, de igual manera se dispone de una serie de escritos y reflexiones sociológicas, económicas y políticas, producto de su meditación personal tras observar formas y maneras distintas de pensar y actuar en los diversos países en que vivió. ${ }^{?}$

En su natal Aguascalientes apenas lo reconocen, la historiografía nacional lo redescubriría hasta mediados del siglo $\mathrm{xx}$, gracias a una serie de publicaciones periodísticas ${ }^{10}$ que dieron cuenta de varios de sus inventos $y$, posteriormente, por otros trabajos de diversos investigadores entre los que podemos citar a: Porrúa ${ }^{11}$ quien reseña algunas de sus principales actividades, González y González ${ }^{12}$ lo identifica como uno de los científicos importantes de finales del XIX, varias citas de investigadores de la ciencia nacionales ${ }^{13}$ y extranjeros ${ }^{14}$ contemporáneos lo mencionan; Trabuls ${ }^{15}$ únicamente lo refiere dentro del apéndice de "Hombres de ciencia"; en la ciudad de México es nombre de calle, referencia que poco o nada dice a los transeúntes.

Esbozar su trayectoria es relativamente fácil (véase anexo núm. 1) si lo que queremos es enlistar sus aportaciones a la ciencia de México, pero poco ilustrativa si deseamos saber más acerca de su conducta, cómo pensaba, qué condiciones sociales vivió que lo fa-

${ }^{9}$ Entre los títulos que podemos reseñar están: “México y sus revoluciones”; “¿Debe el gobierno fomentar el sentimiento religioso para conservar la Unidad Nacional?", "Las dos civilizaciones. Latina y anglo-sajona”, etcétera. Algunos fueron publicados en diarios de la época, la mayoría se quedaron esperando mejores condiciones financieras para salir a la luz.

${ }^{10}$ Diario El Dictamen, México, noviembre de 1951.

${ }^{11}$ Ángel Ma. Garibay K., Proemio, Diccionario Porrúa de historia, biografía y geografía de México, , $3^{\text {a }}$ ed., tomo i México, Ed. Porrúa, 1970.

${ }^{12}$ Luis González y González, La ronda de las generaciones. Los protagonistas de la Reforma y de la Revolución Mexicana, México, Sep, Cultura, Col. Foro 2000, 1984.

${ }^{13}$ María de Lourdes Herrera Feria, "Los actores locales de la modernidad a finales del siglo xix: expositores poblanos en las exhibiciones mundiales", Nuevo Mundo Mundos Nuevos, Coloquios, 2009. http://nuevomundo.revues.org/index $55555 . \mathrm{html}$

${ }^{14}$ US Pat. 493246 - Filed Mar 25, 1892.

${ }^{15}$ Elías Trabulse, Historia de la ciencia en México. Apéndices e indices, Col. Historia de la ciencia en México, México, FCE, 1984. 
vorecieron o limitaron, entre otros etcéteras. La ortodoxia nos recomienda iniciar por los orígenes de nuestro biografiado.

\section{GÉNESIS DE UN CIENTÍfICO MEXICANO DE FINES DEL SIGLO XIX}

Eran las 3:30 de la tarde del jueves 17 de mayo de 1900, en el Salón de Sesiones del Cabildo del H. Ayuntamiento del puerto de Alvarado Veracruz, estaba por materializarse el proyecto de desarrollo urbano y social más ambicioso del país y quizá, del mundo. El salón se encontraba abarrotado con la presencia del Cabildo en pleno y diversos invitados. Se discutió como punto único de la orden del día la aprobación o no, del Acta de Instalación de la "Compañía Proveedora de Agua, Alumbrado y Fuerza Motriz del Puerto de Alvarado S.A. Lda" la cual ofrecía la dotación de dichos servicios a la población bajo la modalidad de concesión por 40 años. El resolutivo de la reunión aprobó por unanimidad la cesión de derechos y al día siguiente se formalizó la Acta de Instalación de la Compañía.

La sesión era producto de una convocatoria pública donde se estableció el objeto de la misma y fue firmada por las autoridades locales y personas distinguidas del puerto. Meses atrás, se había realizado la "Parte expositiva" que daba cuenta del proyecto en lo general. Convencidos de la bondad de la propuesta, se determinó la convocatoria pública a través del Cabildo donde se presentaría a suficiencia la idea total y sus mecanismos de operación.

La compañía no contemplaba únicamente la dotación de servicios a cambio de una remuneración lucrativa, se sustentaba sobre un principio social de fuerte nacionalismo condicionando a que sus accionistas no podrían ser "unos cuantos capitalistas poderosos, por lo regular extranjeros, sino en la que da fácil acceso á todas las fortunas como lo hace la Empresa actual, por medio de una especie de suscripción popular"16

16 "Precedentes que establece la Empresa y bien general que entraña" en Concesión y Estatutos de la Compañia Proveedora de agua, alumbrado y Fuerza Motriz del Puerto de Alvarado S.A. Lda. México, Tip C. Lutteroth, 1900, 33. AP.PAV. ChPed,AM.900/04/12. AAFM-A.V. [0687] 


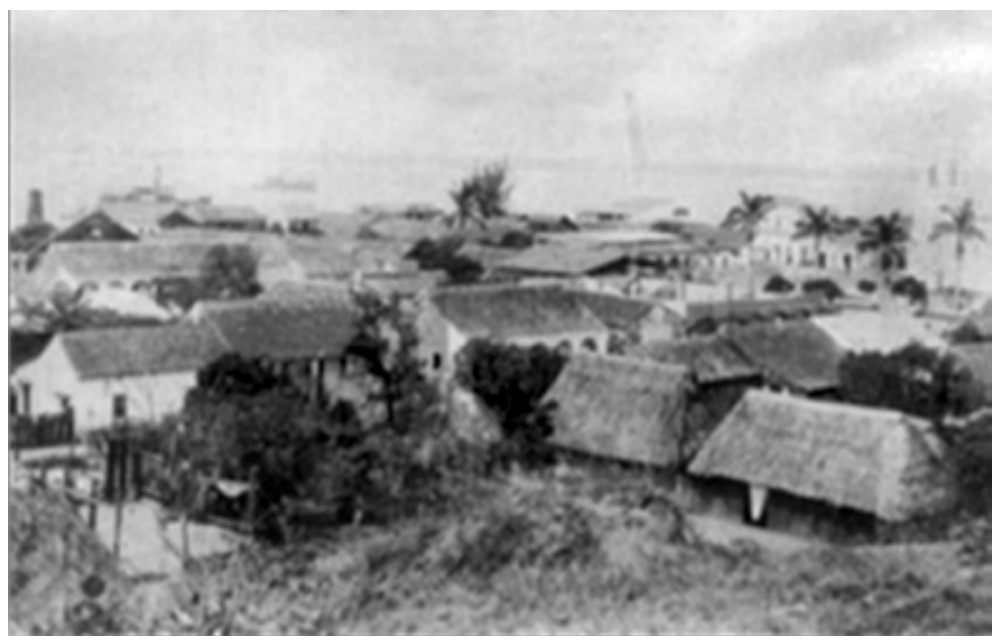

Fото 2. Alvarado, Veracruz, 1900.

alcanzar todo esto de la manera en que la Empresa se propone, esto es, por medio de capital nacional y con la cooperación de todos los elementos sociales, puesto que las acciones son pequeñas y pagaderas á grandes plazos, es lo mismo que despertar el espíritu de empresa, que llegar á grandes resultados con la acción combinada de pequeños esfuerzos, que hacer participar al pobre de las utilidades de los grandes negocios; y en suma todo esto es ejemplar, patriótico y verdaderamente económico. ${ }^{17}$

Los servicios ofrecidos por la Empresa social, se amparaban en los resultados de un año de observaciones minuciosas de la naturaleza, ofertando además de los servicios de agua potable, la energía eléctrica para alumbrado público y privado, los de dotación de drenajes, desarrollo agrícola por riego y el establecimiento de escuelas públicas laicas y gratuitas, con sus respectivas dotaciones de bibliotecas desde el nivel de párvulos hasta el de jóvenes.

Se avizoraba que esto sería propicio para el fomento e instalación de industrias, la creación de empleos debidamente capacitados y, particularmente, ilustrar a la juventud; en concordancia a los Arts.

${ }^{17}$ Op. cit., 34. 


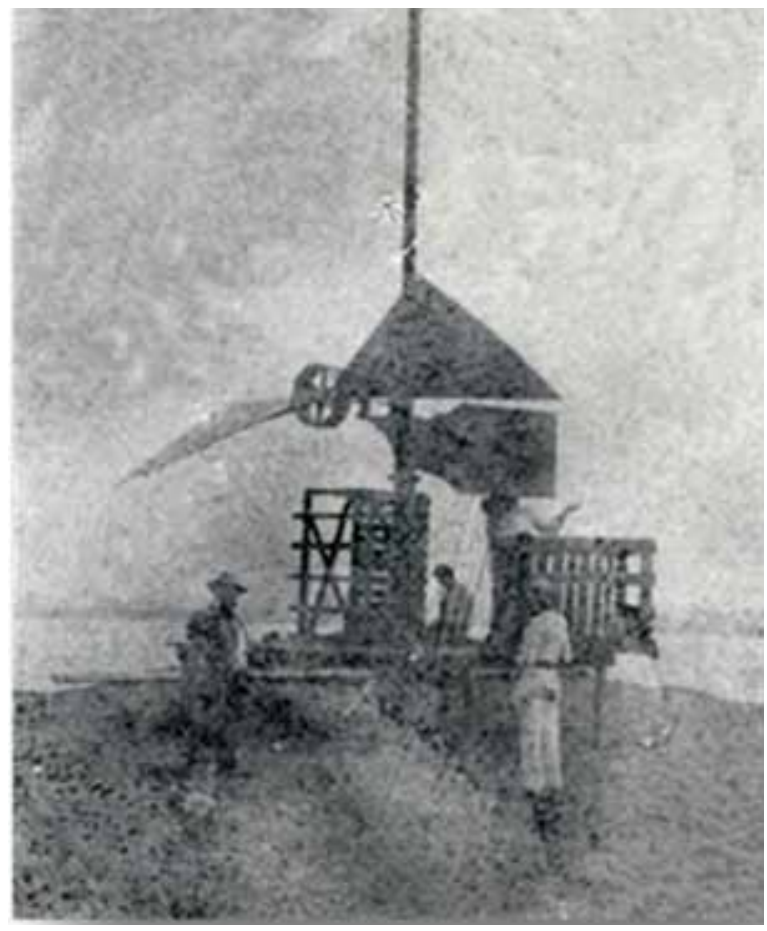

Fото 3. Aeromotor. Los Médanos, Alvarado, Veracruz, 1900. A.M. Chávez, primero de izquierda a derecha.

22 a 29 de la Concesión, que buscaba: "Preocuparse constantemente de los grandes ideales de la humanidad, poner al lado de lo bueno y útil, lo bello y noble, que es más meritorio todavía”. ${ }^{18}$

Los servicios propuestos no eran una novedad en sí, aunque sólo las ciudades más grandes del orbe como París, Inglaterra y Nueva York contaban con ellos de manera regular, la primicia de la propuesta mexicana radicaba en la manera en cómo se concebía la captación de esa energía así como su conducción, pues, su inventor se había percatado que era posible aprovechar la fuerza del viento so-

${ }^{18}$ Ibid. 
bre los médanos, para transformarla en energía por medio de unos aeromotores con el fin de llevar agua potable al poblado; también se aprovecharía la pleamar y bajamar del estero como fuente de energía complementaria en caso de que el aire no fuera suficiente para bombear el agua. Pero, si todos estos recursos llegaran a ser eventualmente insuficientes, se contarían con unas pilas eléctricas capaces de mover los motores (véase anexo núm. 2).

El proyecto era totalmente revolucionario en todos los sentidos, auguraba la transformación completa y radical de un poblado de pescadores, agricultores y comerciantes al menudeo, de escasos 4,500 habitantes, en un puerto a la altura de los mejores del mundo.

A más de una centuria de distancia, estas propuestas continúan siendo temas de vanguardia en el concepto de desarrollo urbanosocial de nuestras poblaciones, en pos de una calidad de vida sustentable e integral.

Era la síntesis de su creador, el Ing. Agustín M. Chávez, en la que recapitulaba una amplia e intensa experiencia en invenciones, análisis y puesta en práctica de un desarrollo tecnológico y social.

Alvarado coronaba así el siglo XIX con una propuesta de desarrollo sin parangón en nuestra nación; sin embargo, todo este gran proyecto fue relegado de los anales de la historia local y nacional cuando el sol aún no despuntaba en el puerto el sábado 6 de septiembre de 1902, al fallecer el Ing. Chávez por un paro respiratorio. Con su ausencia, México perdió uno de sus mejores científicos finiseculares, no únicamente por los descubrimientos que realizó, sino también por su legado filosófico que desarrolló en torno a la ética y a la ciencia.

Un cuarto de siglo antes, la familia Chávez inició su migración paulatina de Aguascalientes a la ciudad de México; debido en parte a que se les identificaba con la filiación juarista y al triunfo de Porfirio Díaz y su ascenso al poder, los nuevos porfiristas ocuparon los puestos claves dentro de la política local y nacional, desplazando a sus antecesores. ${ }^{19}$ Por otro lado, la ciudad de México, representó la posi-

${ }^{19}$ El padre de Agustín M. Chávez fue José María Chávez Alonzo, gobernador de Aguascalientes en dos ocasiones; durante su último mandato fue capturado y fusilado por los franceses en mayo de 1964 en Malpaso, Zacatecas. Su primo paterno, Ignacio T. Chávez Acosta fue gobernador de 1872 a 1875 y senador en 1876. 
bilidad de encontrar mejores oportunidades políticas e intelectuales, así, apoyándose en las amistades cultivadas con anterioridad, entre ellas la de Guillermo Prieto, van estableciendo nuevos vínculos.

Desde joven, al ingresar a la Escuela Nacional Preparatoria, se destacó por sus estudios, pues todavía no cumplía el año como estudiante cuando presentó dos ensayos; uno sobre Funciones de Reproducción ${ }^{20}$ y otro sobre la Ósmosis; ambos trabajos manuscritos, siendo éste último publicado. Al poco tiempo se convertiría en discípulo predilecto de Gabino Barreda.

Simpatizante de las ideas en boga, en particular del positivismo, realizó una serie de impresiones con el fin de difundirlas en México; según puede constatarse en la publicación de 1878, las cuales eran unos cuadernillos, propios para tomar apuntes, formados por 16 hojas cuadriculadas tamaño carta, dobladas por la mitad y cosidas a una portadilla de papel delgado en algún color contrastante, donde constaba el número de entrega, que permitía organizarlas, ya que eran coleccionables y seriadas. Las hojas cuadriculadas del interior se destinaban para la realización de apuntes y en la segunda y cuarta de forros se imprimía el texto de divulgación:

NOTICIAS SOBRE LA FILOSOFÍA POSITIVA.- Los principios de la filosofía positiva son conocidos en México desde el año de 1852, época en que regresaron á su país jóvenes mexicanos que habían escuchado en Paris las lecciones de Agusto Comte.- Desde entonces hasta 1868 esos principios no fueron profesados, sino por un pequeño grupo de hombres de ciencia, entre los cuales ocupaban los primeros puestos los discípulos de Comte.- El más notable de ellos por el alcance de sus facultades y por la profundidad de su instrucción científica, ha sido el Sr. Gabino Barreda [...]. ${ }^{21}$

Agustín era romántico, a pesar de tener la rigurosa influencia del positivismo. Entre su abundante correspondencia amorosa, se encuentran múltiples ideas acerca de conceptos como la pureza, el

${ }^{20}$ Trabajo de 44 cuartillas cosidas a mano. AP.PAV. ChPed,AM.878/10/06.I-1. ap/ bio. [0001]

${ }^{21}$ AP.PAV. ChPed,AM.881/04/00.I-1. ap/fis. [0005] 


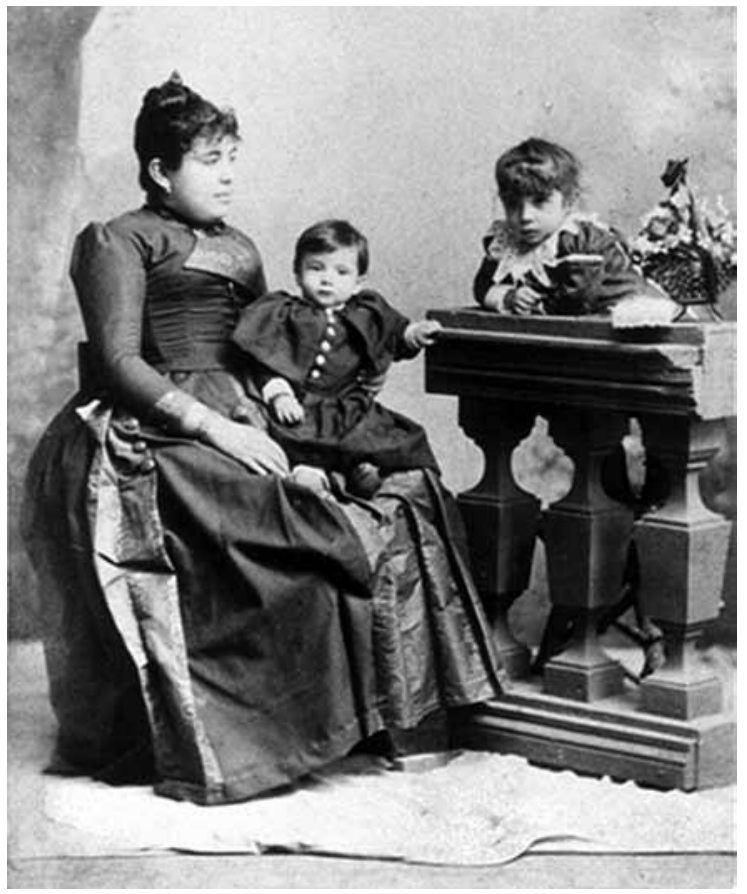

Foтo 4. Familia Chávez Ramírez. Ciudad de México, 1889.

amor y el racionalismo, entreverados con manifestaciones emotivas rayanas en lo poético.

En varias cartas, dedicó a su enamorada diversos poemas titulados según el lugar y momento de inspiración: ; Qué Hermosa Tarde! Una Abeja Dichosa; ; Cuánto se parece a ella!'También le transcribió fragmentos y frases de pensadores destacados como Virgilio, Shakespeare, Cervantes, Sheller, John S. Mill, por ejemplo. Sus escritos de juventud, constituyen, entonces, una amalgama de positivismo y romanticismo, fácilmente discernibles, como lo deja ver el siguiente párrafo: "A veces, también, creía encontrar en mis libros el secreto de mi dicha y el único medio de hacerme cara la existencia; pero nó, la ciencia habla esencialmente a nuestras facultades intelectuales; $y$ 
la vida del espíritu, no es sólo razón, es voluntad también, y más que todo, al menos en mí, sentimiento". ${ }^{22}$

El 18 de mayo de 1886, dos meses después de su matrimonio con Juvencia Ramírez, Chávez sustentó su examen profesional en el Palacio de Minería obteniendo el título ${ }^{23}$ por unanimidad de Ingeniero telegrafista.

La congruencia entre el pensar y el hacer fue parte del rigor de su Método de vida que evaluó y practicó cotidianamente, fiel a su idea de ciencia como expresión de conocimiento sistematizado, construido mediante observaciones, razonamientos y pruebas metódicamente organizadas, no se permitió flaquear un ápice en ninguno de los aspectos más regulares de su vida, manteniendo una clara postura laica, más próxima a la postura anticlerical, tal y como podemos observar en el siguiente párrafo:

Llevo tres días apenas en este pueblo y ya estoy aburrido; $\mathrm{p}^{\circ}$ no es $\mathrm{q}^{\mathrm{e}}$ la poblacioncita sea fea, no, al contrario; [...]. A mí me aburre, sobre todo, tanta, tanta mochería [...]; esto está en poder de los curas $i q^{\mathrm{e}}$ estado tan retrógrado ha sido siempre este! $\mathrm{Q}^{\mathrm{e}}$ no sería con los elementos naturales de riqueza $q^{e}$ posee, si fuera siquiera un poquito liberal! Bueno $\mathrm{p}^{s}$ como estoy solo, mi atención, mis ideas, \& giran sobre estos puntos $q^{e}$ ya sabes cuánto me atormentan sin $q^{\mathrm{e}}$ yo lo pueda evitar: me quisiera comer vivos á los frailes y hasta los gobiernos mismos $q^{e}$ considero más responsables, $y$ estas cosas me hacen muy mal estómago y creo $q^{\mathrm{e}} \mathrm{p}^{\mathrm{r}}$ eso no se me quita la tos, ni me alivio cosa apreciable. ${ }^{24}$

Por demás, Agustín M. Chávez siempre se involucró en la solución a aquellos problemas técnicos que en su época eran prioritarios; como científico e inventor puso a consideración de su país las mejo-

${ }^{22}$ AP.PAV. ChPed,AM.884/08/17.I-1. car/ms. [0010]

${ }^{23} \mathrm{Su}$ tesis constó de 28 páginas manuscritas, con dibujos y cosidas, a la que tituló: Papel De La Tierra En Las Comunicaciones Telegráficas. Dividiendo el contenido de la misma en: Papel de la tierra en las comunicaciones telegráficas, Teoría de la sección, del potencial, de la difusión, de las derivaciones y Verificación. AP.PAV.ChPed,AM.886/06/19.I-1. tes/ms. [0163 y 0164]

${ }^{24}$ AP.PAV. ChPed,AM.899/08/01.I-2. car/ms. [0660] 
res soluciones para el campo y la ciudad, sin embargo, las condiciones políticas, culturales y estructurales de México (laboratorios, equipamiento, apoyos económicos y demás) no estaban dadas para que se pudieran desarrollar cabalmente dichas propuestas; motivo por el cual muchos de estos inventos los probó en su casa, en un cuarto de azotea habilitado como taller, donde tenía un torno, algunos motores, pilas y varios aparatos más. Sin embargo, ciertas pruebas, por su dificultad, no podían realizarse allí, por lo que tenía que trasladarse al taller de la Escuela Nacional, donde trabajaba después de las últimas clases, generalmente de noche.

A partir de 1893, Chávez radicó en Chicago, luego de cumplir con la asignación de "Comisionado de México a la Exposición Internacional de Chicago" en aquella ciudad desarrolló una fórmula para encontrar, sin necesidad de experimentación, el ángulo ideal para obtener mayor rendimiento de una hélice y, por lo tanto, mayor velocidad. Los primeros ensayos fueron muy esperanzadores y la idea fue sometida al análisis de la Scientific American ${ }^{25}$ para buscar su patente; sin embargo, Chávez creía que era en México donde se debería aplicar su invento en lugar de la marina de los Estados Unidos, para lo cual solicita el apoyo de Protasio Tagle quien le respondería, once meses después lo siguiente:

He tardado en contestar su carta por que deseaba comunicarle algo favorable, pero la situación no varía ni cambiará pronto, y me resuelvo á escribirle sobre algunos de los puntos que contiene su carta.

Me escribe Ud. sobre sus trabajos sobre las HÉLICES de los barcos, y los adelantos que ha hecho; pero después de encomiar esa mejoras, resulta que Ud. no puede sacar ningunas utilidades por falta de diez mil pesos para la práctica de todos sus estudios que así quedan reducidos á pura teoría. Ya sabe Ud. cuánto me apena que Ud. le pase constantemente este resultado con sus estudios y que otros saquen el provecho que á Ud. corresponde. $^{26}$

${ }^{25}$ Véase anexo núm. 3

${ }^{26}$ AP.PAV. ChPed,AM.895/01/11.I-2. car/ms. [0489] 
No dándose por vencido solicita respetuosamente del apoyo de su país para poder concretar varios de sus inventos, y decide escribirle a Matías Romero, misiva que conocemos gracias a una copia fiel que conservó el Ing. Chávez:

2107, Michigan Av., Chicago.

Marzo 1o. de 1894

Sr. Lic. Dn. Matías Romero

Washington

Sr. de todo mi respeto y estimación:

Entre mis proyectos tengo los de otras tres máquinas agrícolas que son: una segadora para la caña de azúcar, una sembradora para toda clase de granos y una máquina de romper henequén ó cualquier otro agave.

La primera máquina la construí en México y la ensayé en la Hda. de Dn. José del E. de Morelos, con un éxito completo. Monté un pequeño taller, gasté más de dos mil pesos en eso y en preparar ó habilitar unas 20 segadoras, pues varios hacendados me hicieron pedidos de ellas. Como me faltaba capital para compra de carbón y para pagar á los obreros, propuse el negocio al Sr. Alberto Camacho, a españoles ricos, quienes solamente me dieron esperanzas. Cuando solicité la patente del arado Triplex en este país, solicité á la vez la de la segadora, de cuyo importe tengo adelantados $\$ 20$ a lo que los Srs. Mena y C. de N.Y.; pero por falta de los $\$ 40$ restantes no tengo todavía dicha patente.

La segunda máquina ó sembradora la construí y ensayé en París también con éxito muy satisfactorio, justamente la víspera de salir para México: yo no podía permanecer más tiempo en París por que igualmente los recursos me faltaron, recursos que tenía formalmente ofrecidos. Acompaño dos fotografías de dicha máquina.

También dejé en París casi terminado el modelo de un motor rotatorio de vapor el cual debe producir un rendimiento $10 \%$ más que los actuales.

No he podido todavía continuar el modelo de la raspadora, cuya idea elaboré en México poco antes de venir acá.

Quisiera informar á Ud. de la gran sencillez, rendimiento y demás ventajas de la raspadora, pero no debo, yo mismo, abonar mis invenciones. 
Además del arado Triplex tengo otro proyecto de arado ó mejor dicho procedimiento especial fundado en el principio de "La División del trabajo", por cuyo medio juzgo cederá la producción de los surcos á mano, esto es, arar a mano. Tanto así es de ventajo(so) el sistema que tengo enteramente listo para poder patentar y ejecutar.

Ud. comprenderá de cuanta importancia sería para la agricultura de mi país poseer las máquinas expresadas, sobre todo en las presentes circunstancias de la gran depreciación de nuestra moneda.

Creo que si yo pudiera regresar á México con las patentes y modelos respectivos, encontraría fácilmente el capital después de convocar, secundado por la protección del Gral. que seguramente no me fallaría, á un gran concurso experimental en la Escuela de Agricultura.

Pero para llevar á cabo mis pensamientos, necesito, indispensablemente desde ahora, la liberal protección de mi Gobierno.

He hecho mis cálculos, lo más económicamente posible de todo lo que necesito. No pretendo mucho, con (\$700) setecientos pesos oro obtendré patentes y modelos que me faltan, arado, División y la raspadora, así como el del pantógrafo que es de grandísima utilidad para el deslinde de terrenos por la rapidez y economía con que se hacen los levantamientos respectivos. Permaneceré en este país unos 3 ó 4 meses más consagrado á mis trabajos, de los cuales iré dando á Ud. cuenta pormenorizada. En este sentido deseo escribir al Sr. Presidente.

Si Ud. me hiciera el gran favor de recomendarme con él ó con el Sr. Limantour, como Ud. lo juzgue más conveniente, creo que mi petición sería obsequiada.

Yo procuraré hacerme digno de su recomendación poniendo de mi parte todo mi empeńo y actividad. ${ }^{27}$

Matías Romero le contestaría el mismo día comunicándole:

Washington. Marzo 1o. de 1894.

Señor Ingeniero Don Agustín M. Chávez.

Chicago.

${ }^{27}$ AP.PAV. ChPed,AM.894/03/01.I-2. car/ms. [0409] 
Muy Señor Mío:

Remití á Ud. copia de una carta que me ha dirigido el Sr. William H. Doolittle, el abogado de Patentes á quien recurrí para ver si podía venderlas á Ud., con el objeto de que le dé Ud. el informe que pide. Sería bueno que se dirigiera Ud. al Sr. Doolittle, directamente para evitar la pérdida de tiempo que ocasiona el que lo haga Ud. por mi conducto.

Soy de Ud. atento y seguro servidor.

M. Romero.- Rúbrica. ${ }^{28}$

En su haber científico podemos contabilizar más de una veintena de inventos diversos, tales como arados, segadoras, motores de vapor y eléctricos, pilas, hélices, frenos para tranvías, aeromóviles y otros más. De estos, dos fueron de llamar la atención de los parisinos durante la Exposición Universal de París de 1889; el desarrollo teórico-práctico sobre la resistencia del aire aplicado al aeromóvil, premiado por La Sociedad Francesa de Navegación y posteriormente patentado en París en 1890; otro invento homenajeado fue su Arado Metálico Chávez Triplex, probado en México con éxito, siendo su uso extendido en el agro nacional, este instrumento agrícola fue premiado en el pabellón de implementos agrícolas de la Exposición Universal de París y patentado en Bruselas en 1891, posteriormente, en 1893 fue patentado nuevamente ante la American Scientific de Nueva York. Además se contabilizan 17 ensayos diversos: históricos, sociológicos y técnicos. Con la expectativa de contar con los recursos financieros para desarrollar a plenitud y probar varios inventos constituyó, en diferentes momentos, más de cinco asociaciones, clubes y compañías nacionales e internacionales; empero no cumplieron sus objetivos en virtud del egoísmo y voracidad de sus socios.

Fue invitado a trabajar en el gobierno federal un sinnúmero de ocasiones, rechazando la mayoría de ellas; cuando aceptó fue más por necesidad económica que por identificación a la cultura buro-

${ }^{28} \mathrm{Ibid}$. 
crática. Sin embargo, su ferviente nacionalismo y las altas expectativas de materializar algunos de sus conocimientos en asuntos prácticos de beneficio para México, le otorgaba la esperanza necesaria para desempeñar el cargo. Entre las funciones más relevantes que desempeñó - por demás exitosamente- fueron: Jefe de la Sección de Maquinaria Agrícola en el pabellón de México para la Exposición Universal de París (1889); Comisionado de México a la Exposición Internacional de Chicago (1893); Director General de Telégrafos Federales (1895); Representante de México ante E.U. en el Congreso Postal Universal en Washington (1896); Inspector de Ferrocarril de Veracruz a México (1899); Delegado del Gobierno Mexicano a la VI Reunión del Congreso Internacional de Caminos de Fierro en París (1900).

\section{Los diarios PERSONALES de Chávez COMO MÉTOdo DE VIDA}

Cuando el lector se percata de la gran actividad y producción de vanguardia tanto en lo intelectual como en lo laboral que obtuvo Chávez, a pesar de las penurias y obstáculos, no deja uno dejar de preguntarse: ¿Qué lo inspiró al desarrollo de tales modelos intelectuales, morales y emocionales para lograr sus objetivos? ¿Cuál era su cosmovisión? ${ }^{29}$

De su archivo personal, se dispone documentación suficientemente detallada que nos permite asomarnos al origen del conocimiento que lo inspiró, así como del procedimiento racional (metodológico) para su quehacer. Este atisbo nos remite a sus años juveniles, aún como estudiante de la Escuela Nacional Preparatoria, específicamente en el año de 1878, cuando encontramos sus primeros apuntes de su "Método de vida", texto inédito, de carácter privado, en el que solía consignar autoevaluaciones muy rigurosas,

${ }^{29}$ Entendida como el conjunto de opiniones y creencias que conforman la imagen o concepto general del mundo que tiene una persona, época o cultura, a partir del cual interpreta su propia naturaleza y la de todo lo existente. Una cosmovisión define nociones comunes que se aplican a todos los campos de la vida, desde la política, la economía o la ciencia hasta la religión, la moral o la filosofía. 
incluyendo aspectos como: higiene personal, horas de estudio, horas de trabajo, moral, y otros de carácter igualmente ético. Miranda Ojeda ${ }^{30}$ nos refiere que

Durante el siglo XIx floreció en México un conjunto de obras de carácter social que pretendía normar los valores, actitudes, comportamientos, gestos, etc., con la intención de esculpir el modelo de ciudadano moderno. [...] con la firme convicción de que los hombres [y las mujeres] arrogados a tales principios favorecían la edificación de una sociedad culta, moderna y progresista, divorciada de las maneras impropias de las sociedades atrasadas.

Se puede identificar que durante la "pax porfirista", fue el apogeo en la edición y divulgación de diversos manuales de buenas costumbres y obras afines, gracias al desarrollo económico que contribuyó al afianzamiento social de una parte de la sociedad que se auto enarboló como la portadora de los "valores más excelsos", emulando a la Europa victoriana.

En general,

[...] Los principios de la urbanidad destacaban la importancia en el arreglo de la casa, en el manejo de los criados, la mesa, la disposición de las comidas, el aseo, los bailes, las visitas, las cabalgatas, el juego, el cortejo y la boda, los restaurantes y cafés, el teatro, los viajes a caballo y en tren, en hoteles y restaurantes, el uso del tabaco, del chicle y el teléfono, las visitas a enfermos, los regalos, los maestros, las cartas, el templo y los niños. Incluso se presentaban observaciones especiales para las mujeres, más obligadas que los hombres a ser cultas, discretas y modestas. ${ }^{31}$

El origen de estos manuales es bien conocido y podemos rastrearlos
en las costumbres cortesanas de Europa; los primeros escritos de ese

${ }^{30}$ Pedro Miranda Ojeda, "Los manuales de buenas costumbres. Los principios de la urbanidad en la ciudad de Mérida durante el siglo xIx", Takwá, Universidad Autónoma de Yucatán, núms. 11-12, primavera-otońo 2007, 131-155.

${ }^{31}$ Patricia Londońo Vega, "Cartillas y manuales de urbanidad y del buen tono. Catecismos cívicos y prácticos para un amable vivir”, en Revista Credencial Historia, núm. 85, 1997. 
tipo fueron una serie de reglas redactadas en pleno Renacimiento que retomaban códigos morales de los Caballeros e Hidalgos de la Edad Media. Erasmo de Rotterdam, en 1530, publicó su De civilitae morum puerilium libellus; paralelamente múltiples escritos surgieron y se fueron enriqueciendo y adicionando hasta lograr verdaderos manuales o guías de "Civilidad y Buen Gobierno", principios fundamentales que favorecieron el desarrollo de la ética comercial, las leyes de ciudadanía y protocolos diplomáticos contemporáneos.

De las múltiples ediciones que circularon en México (país) a fines del XIX, sin duda el Manual de Urbanidady Buenas Costumbres de Carreño ${ }^{32}$ publicado por vez primera en 1853 en Venezuela fue lectura obligada. El Ing. Chávez no fue ajeno a esa literatura, sin embargo, el basamento religioso en el cual se fundamentaban no era del todo concordante con su forma de pensar y de actuar.

Encontró en otros modelos el fundamento con el cual pensaba era más acorde a su ideología particular ${ }^{33}$ y descubrió que en 1748 , George Washington había copiado a mano un escrito intitulado: Rules of Civility \& Decent Behavior in Company and Conversation ${ }^{34}$ que no era otra cosa que una serie de recomendaciones deontológi$\mathrm{cas}^{35}$ aplicables al comportamiento correcto tanto en sociedad como en los negocios. El documento original data de 1595 redactado por jesuitas franceses, había sido traducido al inglés en 1640 por Francis Hawkins. ${ }^{36}$

El principio ético sobre el que Chávez construyó su Método de vida tiene un basamento de moral cristiana, al reconocer principios

${ }^{32}$ Manuel Antonio Carreño Muñoz, Caracas, Venezuela, 1812, París, Francia, 1874.

${ }^{33}$ El concepto de ideología es semejante, pero se diferencia del de cosmovisión (Weltanschauung) en que éste se proyecta a una civilización o cultura entera (cosa que también puede decirse del concepto de ideología dominante) o se restringe a un individuo (limitación que difícilmente podría aplicarse a los raramente usados conceptos de ideología particular o individual).

${ }^{34}$ www.foundationsmag.com./civility.html

${ }^{35}$ Como conjunto ordenado de deberes y obligaciones morales que tienen los profesionales de una determinada materia.

${ }^{36}$ (1628-1681) Jesuita inglés; niño prodigio y traductor. Aún muy pequeño, realizó dos traducciones que le dieron fama y a los 10 ańos de edad publica An Alarum for Ladyes, traducción directa de La Serre. 
universales como la justicia, la humildad, generosidad, economía (ahorro), entre otros; adaptado a la nueva visión social que se pretendía construir, más cercana a las ideas republicanas y liberales de Lucas Alamán y José María Luis Mora y, adicionando aquellos que la ciencia positiva iba aportando.

Sus escritos de 1878 nos permiten reconstruir el origen de su $M e ́-$ todo de vida, primero como un listado de asuntos diversos de carácter personal tales como: adeudos financieros y pagos realizados, fechas de aniversarios, recordatorios de pendientes entre otros, anotados en un cuadernillo de bolsillo que cargaba consigo; posteriormente fue combinando éstos con una serie de estímulos, consejos y recomendaciones para lograrlos, sin embargo, tenerlo en cuenta o cumplir con ellos, no fue suficiente, tuvo la necesidad de evaluar el cumplimiento de los mismos, lo que lo llevó a emplear una serie de letras, números o símbolos que le permitiera conocer el alcance o cumplimiento de sus compromisos y visualizar sus logros a través de un cuadro sinóptico. En dicho año podemos leer el siguiente criterio:

$(\alpha)$ Inaugurar mis trabajos de Colegio sin faltar á ninguna de las clases de Historia Natural y de Lógica, y así seguir todo el año haciendo cuanto pueda de mi parte $\mathrm{p}^{\mathrm{a}}$ no faltar. Una (1) [ele] indicará una falta de lógica, así como una b ý una z lo serán para Botánica ý Zoología. Ocuparán su lugar correspondiente en la $4^{a}$ línea horizontal. Compararme a este plan: Historia Nral.; 3 á $4_{\mathrm{m}}$ y 10 á $11_{\mathrm{m}}$. Lógica.- desde 3 thasta después de clase de Literatura. Disertación.- Ocurriendo hasta $10_{\mathrm{m}}$. Francés.- media á las 3 . a la $3^{\text {a línea. }}{ }^{37}$

Múltiples pensadores fueron integrando el marco conceptual que Chávez requería para su Método, precisamente de lecturas asiduas de Pericles, Virgilio, Shakespeare, Cervantes, Sheller, John S. Mill, Bain, Franklin, Washington, Duruy, Chesterfield entre otros más, para construir los criterios que consideraba pertinente observar, sin perder la referencia bibliográfica de donde la obtuvo, para luego hacer una recapitulación de la idea central, a modo de su principio:

${ }^{37}$ AP.PAV. ChPed, AM. 880/01/01.I-1. Obj/per. [003] 
¿Debe un hombre hablar en alabanza suya? No, el héroe de su propia relación siempre embaraza y disgusta á la compañía, $\mathrm{q}^{\mathrm{e}}$ no sabe $\mathrm{q}^{\mathrm{e}}$, hacer, ni $\mathrm{q}^{\mathrm{e}}$ decir, ni q aspecto presentar. ¿Debe hablar de sí mismo? No, la vanidad es el origen tanto de su condenación como de su panegírico.

Un secreto conveniente es el único misterio de los hombres capaces, el misterio solo es el secreto de los débiles y de los arteros.

El hombre q $q^{\mathrm{e}}$ no dice nada ó el que lo dice todo, no será jamás el confidente de nadie.

Si un necio sabe un secreto, lo descubre $\mathrm{p}^{\mathrm{r}} \mathrm{q}^{\mathrm{e}}$ es necio; el bribón lo revela $\mathrm{p}^{\mathrm{r}}$ $\mathrm{q}^{\mathrm{e}}$ así conviene a sus intereses. Chesterfield. (Pag.13). ${ }^{38}$

Este razonamiento la resumiría de la siguiente manera: "No habléis $\mathrm{p}^{\mathrm{a}}$ ti mismo, á causa de ti mismo, ni contra ti mismo, sino deja $\mathrm{q}^{\mathrm{e}}$ tu carácter hable $\mathrm{p}^{\mathrm{r}}$ ti."

Luego de una serie de reflexiones posteriores, en el diario mismo anotaba los documentos que era necesario confrontar o complementar para un análisis más detallado y redactar nuevamente la idea; en este caso Chávez anotó: "Cartas, Pag. 342", en clara referencia de cotejar aún más esa idea. Finalmente de este juicio formaría su principio número 2 intitulado "Silencio" como parte de su evaluación personal.

Esta plasticidad de método le permitió adaptarlo a los requerimientos técnicos y filosóficos que él mismo iba descubriendo o necesitando, motivo por el cual no lo podemos concluir como una regla generalizadora, sino estrictamente personal y circunstancial.

Entre los principios que en 1878 consideró meritorio observar estuvieron:

1. Templanza. No comáis en exeso [sic] ni bebáis hasta aturdiros.

2. Silencio. No digáis masque [sic] lo que pueda servir á los otros ó á nos mismos. Evitad las conversaciones osiosas [sic].

3. Orden. Que cada cosa en nos tenga su lugar y cada negocio su tiempo.

${ }^{38}$ Ibid. 
4. Resolución. Tomad la resolución de haced lo $\mathrm{q}^{\mathrm{e}}$ debéis hacer; $\mathrm{y}$ cumplid sin faltas lo $\mathrm{q}^{\mathrm{e}}$ habéis resulto.

5. Economía. No hagáis gastos masque [sic] $\mathrm{p}^{\mathrm{a}}$ el bien de los otros ó $\mathrm{p}^{\mathrm{a}}$ el nuestro, es decir, no desperdiseis nada.

6. Trabajo. No perdáis el tiempo. Ocupaos siempre en alguna cosa útil. Absteneos de toda acción $\mathrm{q}^{\mathrm{e}}$ no sea necesaria.

7. Sinceridad. No uséis de ningún mal precepto; pensad con inocencia y justicia; hablad con prescisa.

8. Justicia. No perjudiquéis a nadie, sea agravándole, se despreciando hacer el bien al cual vuestro deber os obliga.

9. Moderación. Evitad los extremos, guardaos de resentir las injusticias $\mathrm{q}^{\mathrm{e}}$ os paresca $[$ sic $]$ merecerlas.

10. Aseo. No sufráis ningún desalińo ni sobre nuestro cuerpo, ni en nuestro vestido, ni en nuestra casa.

11. Tranquilidad. No os dejéis turbar $\mathrm{p}^{\mathrm{r}}$ vagatelas, ni accidentes ordinarios ó inevitables.

12. Humildad. Ymitad á [sic] Jesús.

Prácticamente se conservan la totalidad de sus diarios (1878-1902) donde anotó su Método de vida, lo que nos permite observar los cambios y transformaciones que ańo con año realizó tanto en sus principios, como en los símbolos desarrollados por él mismo, siendo cada vez elaborados y multirrepresentativos con la finalidad de mantener mayor congruencia con los principios, pero específicos en la evaluación.

No es pues la intención el realizar un análisis a detalle de los mismos, ya que a falta de conocimiento preciso de sus mapas mentales que lo llevaron a reflexionar y anotar, o no, ciertos principios y sus correlaciones, el riesgo de interpretación es considerable. Además por razones de espacio, únicamente mostraré su Método de vida comprendido entre los ańos de 1878 a 1880.

En mayo de 1878, realizó autoevaluaciones por día y semana de cada uno de sus doce principios, contabilizando para cada uno de ellos dónde habría que corregir. Al principio fueron de seguimiento simple en cuanto a cumplimiento o no, tal y como lo podemos constatar en la foto 5 . 


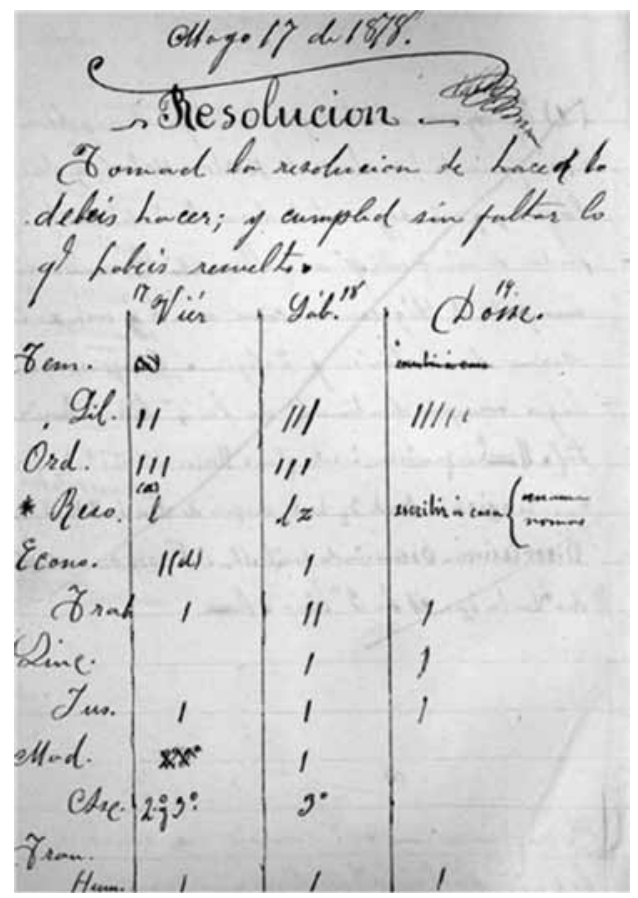

Foто 5. Resolución.

Chávez anotó: "Hasta no satisfacer estos principios dejaré de anotar su falta estando pendiente (/)".

Podemos apreciar entonces que el principio 11 "Tranquilidad" (foto 6) fue el único que se cumplió $100 \%$; no así para el de "Silencio", es el que más faltas tuvo según su propio sentir al anotar 10 faltas entre el viernes y el domingo. Es pertinente resaltar que el principio 4 "Resolución" enfatiza en qué aspectos no los cumplió cabalmente, en este caso para lógica (1) y zoología ( $z$ ); en el aspecto de "Aseo" hubo omisión o incumplimiento en relación con el principio $2^{\circ}$ y $3^{\circ}$.

No había escala máxima o mínima, únicamente cuantificaba los principios cumplidos y efectuaba semanalmente una suma temática para llevar un control de qué tanto se había regido su vida 


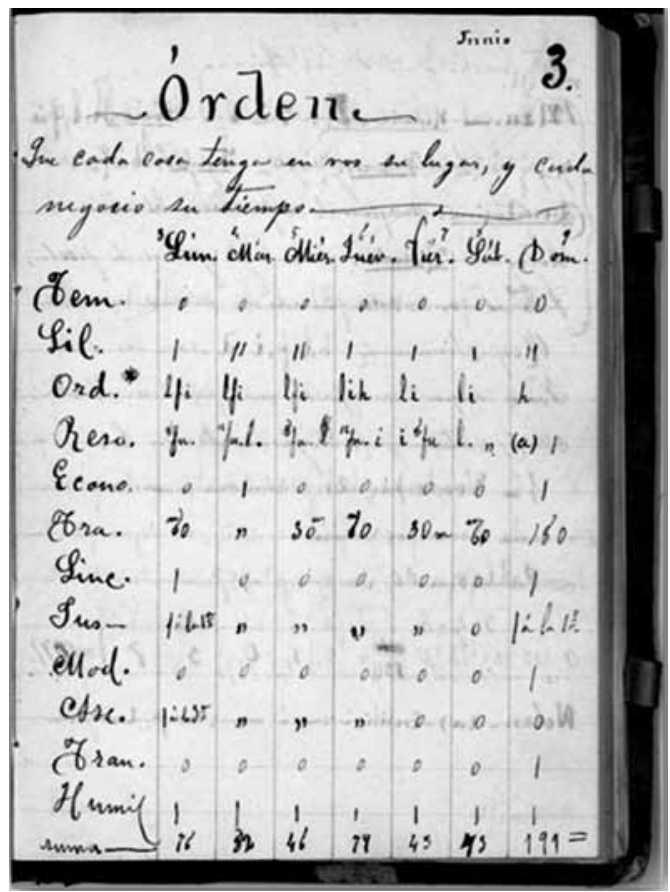

Fото 6. Orden. Junio 1878.

por el método. Cada semana se ponía énfasis en uno de los doce principios.

En el diario presentado en la foto 5, podemos observar que el tema semanal era "Resolución" (resaltado con un asterisco), el siguiente le correspondería a "Economía" y así sucesivamente en el orden consecutivo de los 12 principios ya enlistados.

Los cambios y adecuaciones se ajustaban inmediatamente, en esta evaluación del mes de junio de 1878 se aprecia al pie del cuadro sumas que le permitían por día/semana contabilizar qué principios observar. La suma era simple sin importar las categorías (principios) disímbolas.

El siguiente paso era anotar, al reverso de la semana cumplida, la cuenta resultante y, como el propio Chávez observó, en esa ocasión 


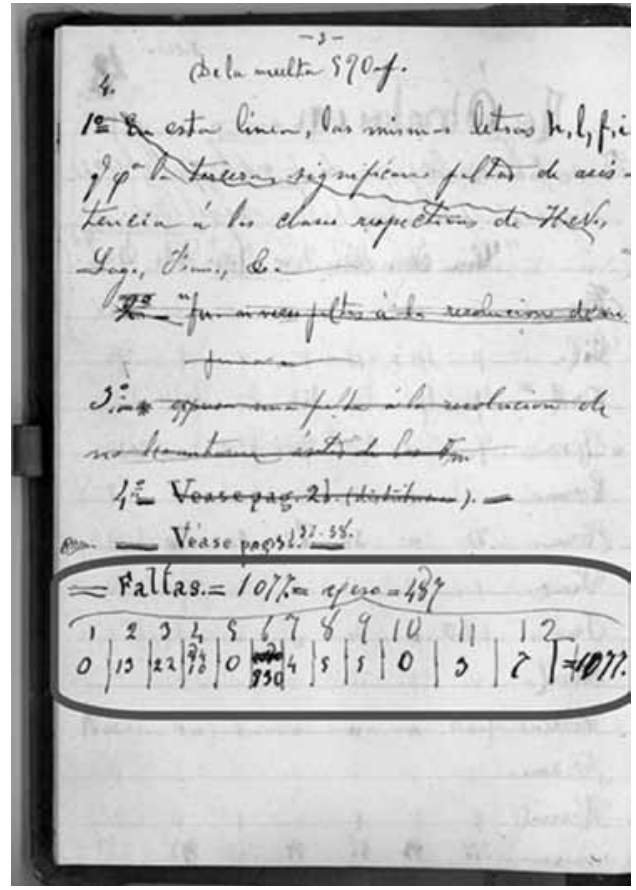

Foто 7. Faltas.

el principio con mayores faltas fue el seis: “Trabajo. No perdáis el tiempo. Ocupaos siempre en alguna cosa útil. Absteneos de toda acción q $\mathrm{q}^{\mathrm{e}}$ no sea necesaria" (foto 7 , recuadro).

Como nos deja observar su documentación personal, esta autovaloración era en exceso crítica, pues sus programas de trabajo semanales nos remiten a horarios desde las 6 de la mańana hasta las 11:30 de la noche de lunes a sábado; con una hora para comida que alternaba entre las 2 y 3 de la tarde o de 3 a 4 según la actividad de cada día de la semana. Esto nos dice mucho de la disciplina que ejercía.

Estas sumas se comparaban semana contra semana del mes en turno para cotejo de cumplimiento, de igual manera al cierre del mes se sopesaba contra los anteriores para, finalmente, al ańo hacer un balance general que permitiría esbozar nuevos principios, símbo- 


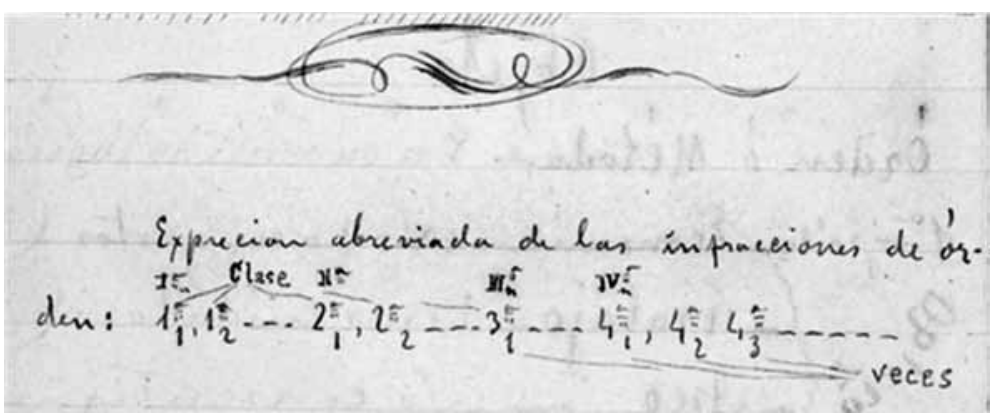

Fото 8. "Exprecion [sic] abreviada de las infracciones de órden".

los (algunos con color, lo que ampliaba mucho la gama de significación) y, por consiguiente la conducta que seguir para el ańo venidero.

Esta guía le permitió establecer criterios normativos personales claros, pero muy rigurosos, que sustituían los valores de moral religiosa y de clara ruptura a las prácticas consuetudinarias, a favor de una ética laica, sobre un principio científico y moderno acorde a las ideas de progreso vigentes. El propio Chávez lo conceptualizaría así: "[...] un trabajo más activo, la fe siempre en las convicciones honradas y la práctica de mejores costumbres". 39

La revisión de las evaluaciones semanales fueron perfeccionándose hasta el establecimiento de fórmulas matemáticas (teoría de grupos) que le permitieran obtener resultados más exactos, tal y como se muestra en este fragmento (foto 8) de enero 1880 donde estableció el criterio.

A continuación podremos apreciar una breve secuencia evolutiva de la especificidad de su Método de vida la cual, por sí misma, es un claro referente de la inteligencia y disciplina que aplicó a los aspectos más triviales de su quehacer.

Para inicio de 1880 ya estaba definido el objeto y sujeto de su Método de vida, el cual establece "en un sentido lógico" como sigue: 


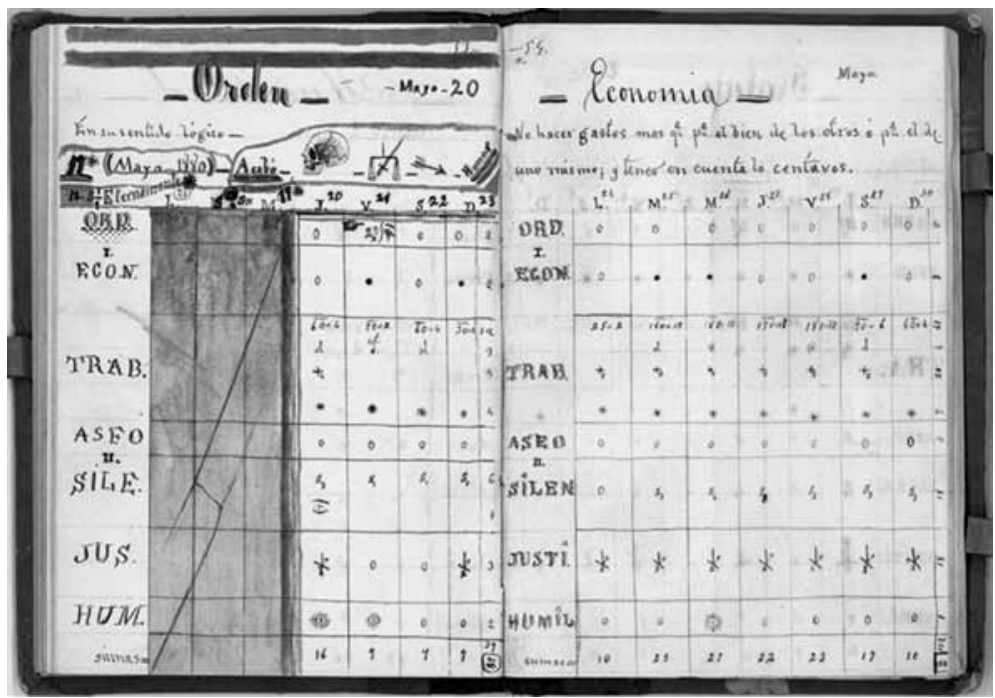

Fото 9. Orden y Economía.

Objeto $\left\{\begin{array}{l}\text { Economia }- \text { No hacer gastos \& } \\ \text { Trabajo - Tener cuidado \& } \\ \text { Aseo - No consentir... }\end{array}\right.$

Sujeto $\left\{\begin{array}{l}\text { Silencio - No decir... } \\ \text { Justicia - No perjudicar... } \\ \text { Humildad - Ymitad á }\end{array}\right.$

La segunda quincena de mayo de 1880, que comprende del 17 al 30; las prioridades semanales fueron: "Orden" y "Economía" (foto 9). Para ese año, el número de principios que evaluar era menor pasando de doce en 1878 a siete, ajustándolo a uno por cada día de la semana, tal y como lo podemos ver en el cuadro 1 . 
Cuadro 1. Principios por evaluar

\begin{tabular}{|c|c|c|c|}
\hline Año & Principio & Año & Principio \\
\hline \multirow[t]{12}{*}{1878} & 1. Templanza & 1880 & 1. Orden \\
\hline & 2. Silencio & & 2. Economía \\
\hline & 3. Orden & & 3. Trabajo \\
\hline & 4. Resolución & & 4. Aseo \\
\hline & 5. Economía & & 5. Silencio \\
\hline & 6. Trabajo & & 6. Justicia \\
\hline & 7. Sinceridad & & 7. Humildad \\
\hline & 8. Justicia & & \\
\hline & 9. Moderación & & \\
\hline & 10. Aseo & & \\
\hline & 11. Tranquilidad & & \\
\hline & 12. Humildad & & \\
\hline
\end{tabular}

A la vista de este resumen pareciera que Chávez decidiera no aplicar, ni actuar en consecuencia, en principios tan próvidos como "sinceridad" o "moderación", por citar sólo estos dos, sin embargo, la revisión constante de los mismos, así como el convencimiento de su pertinencia, lo llevó a complementarlos hasta lograr la síntesis deseada.

Un ejemplo de esto lo podemos observar en sus escritos de abril de 1880 al detallar, producto de nuevas lecturas, la referencia al "Descuido en el poder de la expresión", inspirado o relacionado con los escritos de Bain, ${ }^{40}$ en este caso leído del francés Les sens et Lintelligence, donde cita las páginas para prestar atención.

${ }^{40}$ Alexander Bain (1808-1903). Escoces, filósofo y educador. Profesor de matemáticas y filosofía natural en la Universidad de Glasglow, Inglaterra. Amigo cercano a John Stuart Mill; autor de varios libros entre ellos "Los sentidos y el intelecto" (1855) y "Las emociones y la voluntad" (1859) que lo posicionaron como un investigador independiente. Los temas de su interés versaban en "filosofía moral" y "moral en la ciencia". 


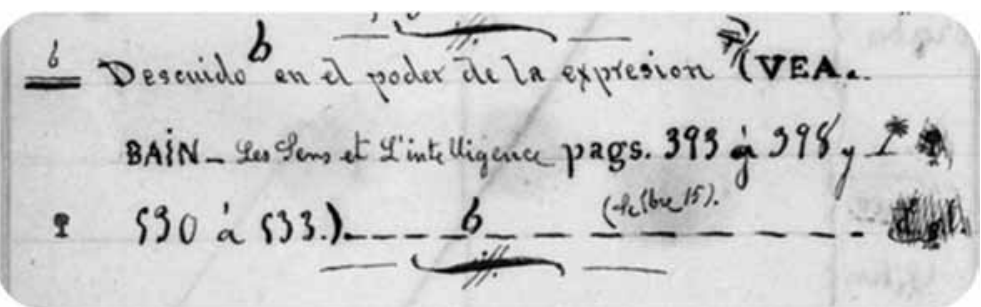

Foто 10. Descuido.

Llama la atención las letras (d. ${ }^{e}$ g.t.) al final de la referencia (foto 10 , en círculo) que fueron tachadas como si de este concepto estuviera buscando alguna fórmula que le ayudara a ponderarlo.

En meses posteriores, abreviaría la anotación de los principios únicamente a la primera letra de cada uno: "O" para orden, "E" para economía, “T” para trabajo y así sucesivamente.

Lo que se puede constatar en las dos imágenes adjuntas (fotos 9 y 11) es la riqueza de los símbolos elaborados, de algunos de ellos sabemos su uso y significado. Veamos algunos ejemplos de éstos, así como de su significado para 1880:

$\mathrm{C}_{1, \mathrm{n} \ldots}$. Centavos mal invertidos en donde la expresión 1 , hasta " $\mathrm{n}$ " era referencia de cantidad.

1. Llevar un libro de cuentas.

p. Arreglarse rigurosamente á un presupuesto, según el fondo de gastos.

O. Como "cero" para 6 de 7 principios, únicamente simboliza "pedir prestado" en relación al principio de economía.

- Dormir más de 7 horas (pr 15 m ó menos una falta).

+ Falta á la distribución (del programa)

* Demorar cualquier asunto.

ע Resolución no cumplida.

Otras fueron más elaboradas como a continuación se muestra:

Algunos símbolos se relacionaban con números para precisar el principio por observar, tal fue el caso del concepto: "No pensar an- 


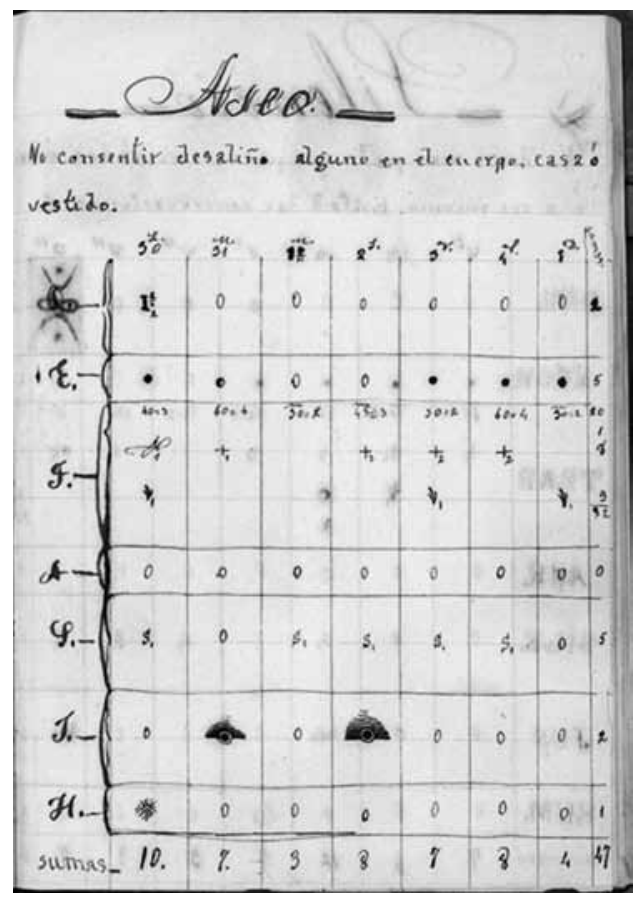

Foтo 11. Aseo.

tes de hablar, ni considerar previamente: oportunidad, personal, lugar, materia, forma y trascendencia”; a estas seis últimas palabras se les asigno un número consecutivo, iniciando con oportunidad (1), hasta concluir con trascendencia (6) (foto 13), las cuales se podían relacionar con otros principios como: "Silencio", "Justicia" e inclusive "Trabajo".

De esta manera cuando autoevalúa en Justicia, con el número adicionado a manera de expresión algebraica, se especifica en qué. Veamos este método ya aplicado (foto 14).

En el primer recuadro del lunes 24 de mayo de 1880 (pag. 30, arriba izquierda), en el principio TRABAJO (tener en cuenta los minutos, y emplear el tiempo de una manera más provechosa que se pueda) hubo una pérdida de tiempo personal (2) de 25 minutos 


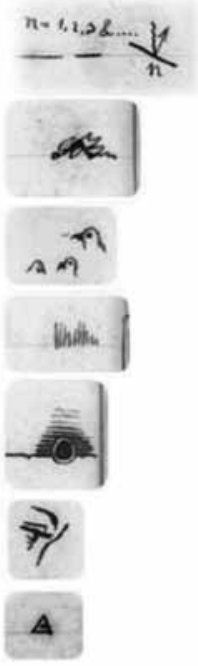

Injusticia

Informalidad

Eludir las conversaciones ociosas

No cumplir, ni escribir un rato después

Dejar pasar 14 días sin escribirla

Descuido en el poder de la expresión

No useis de ningún mal pretexto, personal con inocencias justicia, hablad como pensais

Fото 12. Símbolos.

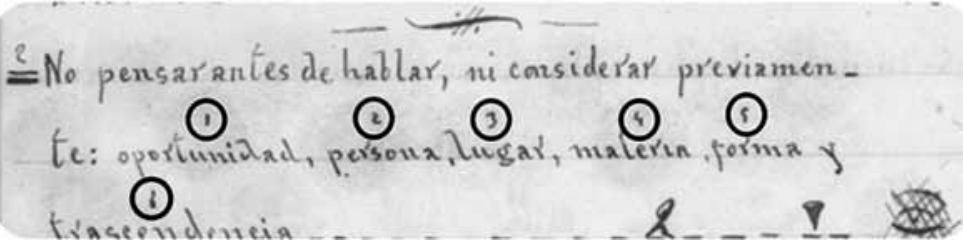

Fото 13. No pensar antes de hablar...

anotado como: $25=2$, de igual manera consideró otro fallo en la distribución del programa (+) en su forma (5) representado como: $+_{5}$, lo que ocasionó demora $\left(^{*}\right)$

Si bien es claro que la lectura directa, hoy día no nos permite conocer con precisión a qué se refería, lo cual podría ser producto de una conjetura que hago, habría que confrontar esta evaluación con la actividad desarrollada en esa época, lo que quizá nos permita 


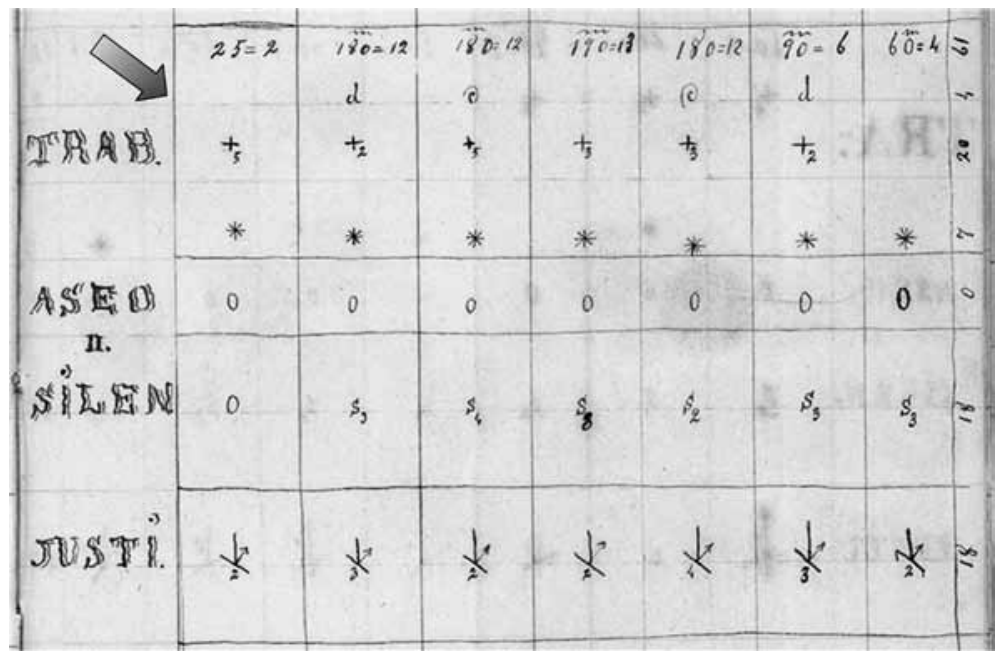

Fото 14. Algebra aplicada.

aproximarnos aún más al sentido aquí interpretado. No perdamos de vista que su Método fue desarrollado para un fin estrictamente personal, totalmente adaptable a las condiciones y necesidades del momento y constantemente revisado, y ajustado. Lo cierto es que los símbolos fueron prácticamente el desarrollo de un lenguaje o código personal complejo.

Es necesario puntualizar que su Método de vida, registrado cotidianamente en cuadernillos de bolsillo, se complementaba al menos con otras tres anotaciones adicionales: el "Método" ya descrito brevemente que era su guía de conducta y acción; su "Programa” que no era otra cosa que la organización horaria de sus actividades; su "Presupuesto" relativo a la contabilidad (ingresos/egresos) especificando concepto y persona; y "Anotaciones" personales donde transcribía párrafos de lecturas realizadas y que servían para nuevas reflexiones y replantear o modificar sus principios y símbolos. Con los años desarrollaría más esas ideas hasta obtener su complemento al Método de vida y que titularía "Amor, Ciencia y Gloria (A.C.G)", tal y como podemos leer a partir de la siguiente reflexión: "Complacer a la inteligencia, descubrir el por qué de los grandes cambios del 


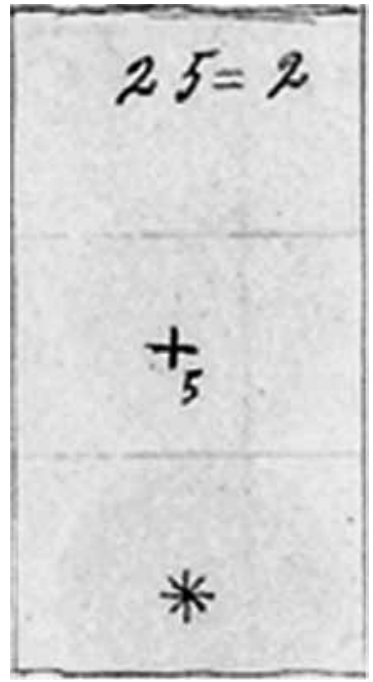

Fото 15. Algebra.

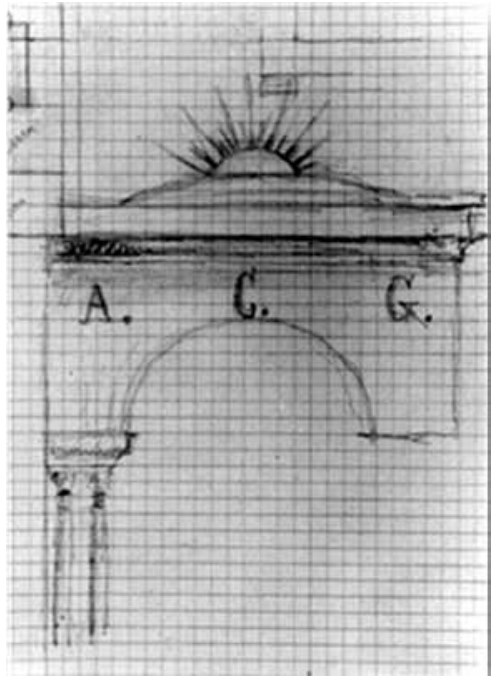

Fото 16. Arco del Triunfo con siglas A.C.G., circa. 1886.

universo; esto es grandioso, eterno: el arte habla al corazón; pero el verdadero Amor habla a todo, estimula a la Gloria y es superior al arte y a la Ciencia en verdad, en grandeza y sentimiento". ${ }^{41}$

Su Método de vida, desarrollado hasta lograr su conceptualización más acabada en A.C.G., era sin duda, el motor filosófico que permitió a este inventor mexicano organizar, producir, reflexionar, investigar y luchar contra todas las adversidades que en su tiempo enfrentó. En varias de sus misivas personales a su esposa Juvencia Ramírez encontramos líneas o párrafos completos donde el propio Agustín lo confirma: "es cierto que cuando se va por un camino que no van todos y se aspira á lo que yo aspiro, todas esas dificultades, todas esas incertidumbres, esperas de resoluciones y demás, son propias é interesantes de las grandes luchas, sin las cuales, los hombres, no podrían hacer más que lo mismo que hace la inmensa mayoría". ${ }^{42}$ 


\section{Palabras finales}

El rápido examen del Método de vida de Chávez nos permite establecer marcaje diferencial con respecto a los "Manuales de Buenas Costumbres", tan de boga en la época; estos últimos de eran una réplica de las costumbres aristócratas de la Europa Victoriana de finales del XIX, donde los avances tecnológicos y económicos favorecieron su difusión y propaganda, al instituirlo como "modelo ideal de civilidad".

Mientras esos manuales, de claro basamento religioso pretendían reforzar las costumbres consuetudinarias al adoctrinar desde el individuo hasta la sociedad y, por ende al Estado, para mantener el statu quo, el Método de vida de Chávez era estrictamente de carácter personal con fines de autodisciplina inspirado en principios o máximas científicos (sociológicos, filosóficos y psicológicos) que él fue retomando o construyendo acorde a los requerimientos de su desarrollo intelectual.

Otra diferencia importante entre ambos es que, mientras los "Manuales" veían en la educación formal un elemento pertinente para los hombres únicamente, Chávez estaba convencido de la necesidad de compartir este conocimiento, como algo ineludible para el entendimiento con la pareja, la mejor formación de ciudadanía y de los hijos; tal y como las siguientes líneas, selección de su correspondencia personal, lo confirma:

Por que tu y yo Juvencia casi hemos sido educados del mismo modo; y creo que si desde un principio nosotros [nos] hubiéramos tratado, siempre habríamos caminado muy tomaditos desde niños de la mano. ${ }^{43}$ [...] si nos ayudamos mutuamente lograremos algunas veces, por lo menos, desconocer por un ladito el velo de la bella y nobilísima ciencia. ${ }^{44}$ Yo he soñado algunas veces, pero con un placer tan grande, que tú y yo haremos algo por la instrucción de nuestra patria; porque los dos amamos mucho eso ¿̇verdad? ${ }^{45}$

${ }^{43}$ AP.PAV.ChPed,AM.885/07/02.I-1. car/ms. [0066]

${ }^{44}$ AP.PAV.ChPed,AM.885/02/10.I-1. car/ms. [0042]

${ }^{45}$ AP.PAV.ChPed,AM.885/09/09.I-1. car/ms. [0095] 
A pesar de ese reconocimiento (algo que hoy en día se pregona como "equidad de género") tanto los "Manuales" como el "Método" compartían ciertos principios de normatividad en conducta y acción como: economía (entendida más como ahorro y que el modelo de desarrollo sustentable ahora retoma), trabajo honrado, respeto, justicia, etcétera, adicionados con otras nociones de clara modernidad $^{46}$ que la ciencia develaba, entre ellas el concepto de higiene.

$\mathrm{Su}$ trayectoria personal se vio truncada con su precoz fallecimiento cuando apenas tenía 47 años de edad, lo que no permite identificarlo como un intelectual que se hubiera declarado abiertamente antiporfirista; sin embargo, en varios de sus escritos es posible asomarnos a una postura clara, decidida y altamente nacionalista, anticlerical ${ }^{47}$ y a favor de las clases más desprotegidas; tal y como lo podemos atisbar en la "Concesión y Estatutos de la Compañía Proveedora de Agua, Alumbrado y fuerza Motriz del Puerto de Alvarado" mencionada atrás.

Tuvo claro, como muchos contemporáneos, del poderío de los imperios europeos y su nacionalismo desbordado que, como sabemos hoy, los llevarían años después a la guerra en todo el continente. La férrea discusión que entabló el Ing. Chávez como representante de México ante en el Congreso Postal Universal en Washington en $1897^{48}$ donde defendió ante la principal potencia (Inglaterra), la reducción o abolición de los pagos de derecho de tránsito es una clara prueba de esta visión. Pero de igual manera su oposición a que "unos cuantos capitalistas poderosos, por lo regular extranjeros", sean los únicos responsables del desarrollo y beneficio nacional, es

${ }^{46}$ La modernidad es la posibilidad política reflexiva de cambiar las reglas del juego de la vida social. La modernidad es también el conjunto de las condiciones históricas materiales que permiten pensar la emancipación conjunta de las tradiciones, las doctrinas o las ideologías heredadas, y no problematizadas por una cultura tradicional. En términos sociales e históricos, no se llega a la modernidad con el comienzo de la Edad Moderna en el siglo Xv, sino tras la transformación de la sociedad preindustrial, rural, tradicional, en la sociedad industrial y urbana moderna; que se produce con la Revolución Industrial y el triunfo del capitalismo.

${ }^{47}$ Muy de acuerdo a las posturas liberales de mediados del siglo XIX.

${ }^{48}$ Velázquez, op. cit., p. 227 y ss. 
una postura interesante donde se reconocían las contradicciones de clases y sus derechos a mejores condiciones.

Respecto a su visión de la pobreza que azotaba a México fue una de sus preocupaciones capitales, que lo llevó al análisis y discusiones con diferentes personas alrededor del mundo; así lo recordaría el propio Agustín en 1900, durante su último viaje por el viejo continente, en el trayecto ferroviario de Roma a París, donde tuvo la oportunidad de entablar diálogo con "unos italianos, luego se animó la conversación. [...] Yo aprendí nuevas cosas de ellos y creo qe [sic] ellos las aprendieron también de mí pr qe [sic] me preguntaban mil cosas con mucho interés, particularmente unos socialistas". ${ }^{49}$

Estas y otras reflexiones fueron veneros para el desarrollo de uno de los documentos más interesantes que el Ing. Chávez haya redactado, su "Ensayo de Economía Política y Filosófica" ${ }^{50}$ En él analiza y define con detenimiento conceptos como: Trabajo, Riqueza, Cambio, al igual que los del valor de la plata y el oro, la moneda, precio, oferta, etcétera. Su exégesis lo llevó a buscar las causas de la pobreza en los individuos (pauperismo) y la riqueza de las naciones. Muchos fueron los autores en que se inspiró, sabemos que entre ellos, la obra El Capital de Karl Marx ${ }^{51}$ fue fundamental.

Influenciado de manera determinante por las ideas positivistas de Gabino Barreda, más que las que pudieran atribuirse a un contacto directo con autores europeos, Agustín M. Chávez constituye un verdadero paradigma de los valores embrionarios de una clase media ilustrada emergente.

Tendencialmente podemos ubicar a Chávez más próximo a un régimen de vida que Juárez caracterizara como la "honrosa medianía”, en un sentido republicano, austero, ilustrado, de fuerte basamento ético y tendencias laicas netamente anticlericales.

Agustín M. Chávez luchó hace 100 años por entregar a su patria proyectos económicos y visionarios con la finalidad de elevar la calidad de vida de los mexicanos.

${ }^{49}$ Ibid., 250.

${ }^{50}$ AP.PAV. ChPed, AM. 898/00/00.I-2 Ap/econ.pol. [0640] (inédito)

${ }^{51}$ Ibid., 176. 
Anexo I

\section{Documentos}

1875 Funciones de reproducción.

1878 Divulgador de "Noticias sobre filosofía positiva". 1880-1902 Desarrollo y aplicación del Método de Vida. 1881 Investigación sobre fenómenos osmóticos. 1886 Tesis. El papel de la tierra en las comunicaciones telegráficas. 1887 Descripción y empleo del anemotorímetro.

1889 Inicia su Ensayo sobre el "valor" que concluiría años más tarde en su disertación sobre Economía Política y Filosófica.

- Tres ensayos: México y sus revoluciones; ¿Debe el G(obierno) fomentar el sentimiento religioso para conservar la $U$ (nidad) $N$ (acional)? y otro, sin título, sobre las diferencias entre las conquistas española e inglesa en América.

- Desarrolló su teoría del anemodinámetro la cual presentó en el Congreso de Aeronáutica de la Exposición Universal. ${ }^{52}$ para operar un aeromóvil (patentado en Bruselas en 1890).

- Estudio sobre Electro-Psychogenese que presentó en la Universidad de la Sorbona de París.

1890 Ensayo de la aplicación del método lógico al estudio de la resistencia del aire. Estudio premiado ante la Sociedad Francesa de $\mathrm{Na}$ vegación. ${ }^{53}$

1893 Conferencista en el Congreso de Electricistas de Chicago.

- Redacta sus ensayos: "Economía, valor de la plata y oro y riqueza de las naciones" y "Las dos civilizaciones. Latina y anglosajona". 1898 Concluye su ensayo de Economía Politica Filosófica.

1901 Artículo "El Positivismo Del Dr. Gabino Barreda”, revista La República.

${ }_{53}$ AP.PAV. ChPed,AM.890/09/22.I-1. ane. [0283] ChPed,AM.891/02/05.I-1. ap/ ane. [0286] 


\section{INVENTOS}

1887 Motor de vapor de émbolo giratorio.

- Motor eléctrico.

1888 Arado metálico Chávez Triplex (probado con éxito en México, Registrado en Bruselas en 1889 y patentado en la Scientific American en 1893).

- Caldera de vasos termohidráulicos con hogar interior.

- Eolipila de émbolos.

1890 Patenta su invento "Apreciación de la navegación aérea aplicado a un aeromobil", en Bruselas. ${ }^{54}$

1891 Segadora Chávez (Máquina para raspar plantas fibrosas como la caña y el maguey).

1892 Premian el "Arado Chávez Triplex” en la Exposición Mundial de Columbia, realizada con motivo del 400 aniversario del descubrimiento de América. ${ }^{55}$

1893 Inventa varios aparatos para ayudarse en su sustento como reparador de diversos instrumentos científicos en Estados Unidos, entre los que contamos con: "Autonivelador de Aparatos Científicos", un "Pantógrafo", "Velocípedo extra rápido y ligero" y una modificación de su "Aeromóvil".

1894 Vende su patente del Arado Chávez Triplex en EU por mil pesos ante el fracaso de su compañía y la precaria situación financiera personal.

- Desarrolla su "Segadora Chávez" impulsada por un motor.

- Desarrolló un método para encontrar, sin necesidad de experimentación, el ángulo ideal para obtener mayor rendimiento de una hélice y, por lo tanto, mayor velocidad. La idea fue sometida a análisis de la Scientific American. ${ }^{56}$

${ }^{54}$ AP.PAV. ChPed,AM.890/10/05.I-1. reg.pat. EU-P/890. [0284]

${ }^{55}$ En dicha Exposición fueron presentadas 2,500 piezas pertenecientes a 65,422 fabricantes, inventores, artistas, etc. Se concedieron 23,757 premios entre medallas y diplomas; los jurados fueron 852, o sea uno por cada categoría o tipo de envío. México ocupó un digno tercer lugar, solamente aventajado por Alemania y Japón. AP.PAV. VCh,JGF.956/08/09.II-3. corr-p/A.Ch-T. [s/n]

${ }^{56}$ AP.PAV. ChPed,AM.895/09/09.I-2. corr/p. [0542] 
1895 Inventa un freno para tranvías.

1900 Inicia sus observaciones de las corrientes eólicas y marítimas en el Puerto de Alvarado, Veracruz.

1901 Desarrollo y aplicación de aeromotores para aprovechar la fuerza del viento y transformar la energía con el fin de llevar agua potable al poblado.

Cargos públicos

1883-1885 Profesor de química y física en la Escuela Nacional Secundaria de Nińas.

1885 Titular de Laboratorio de Telegrafía.

1889 Jefe de la Sección de Maquinaria Agrícola en el pabellón de

México para la Exposición Universal de París.

1893 Comisionado de México a la Exposición Internacional de

Chicago.

1895 Jefe de la Sección $1^{\text {a }}$ de la Secretaria y de Comunicaciones y Obras Públicas.

- Director General de Telégrafos Federales.

1896 Representante de México ante Estados Unidos en el Congreso

Postal Universal en Washington.

1899-1902 Por razones de enfermedad renuncia al cargo de director general de Telégrafos Federales y acepta el de Inspector de Ferrocarril de Veracruz a México ya que en el puerto de Alvarado mejora su salud.

1900 Es nombrado delegado del Gobierno Mexicano para la VI

Reunión del Congreso Internacional de Caminos de Fierro en París. ${ }^{57}$

1901 Su salud empeora y a su regreso a México se traslada a Veracruz en donde se le otorga el cargo de Presidente de la Junta Patriótica Organizadora de las Fiestas del 5 de mayo en Alvarado. 


\section{OtRAS ACTIVIDADES}

1889 Trabajó en el laboratorio de la Sorbona en París con Gabriel Lippmann, ${ }^{58}$ autor del electrómetro capilar.

1892 Crea la sociedad "Chávez y Compañía” con las participaciones de Ignacio Romero Vargas, y de Juan Sánchez Azcona para comercializar su arado "Chávez Triplex". El primero era ministro plenipotenciario de México en Alemania y el segundo enviado extraordinario y ministro plenipotenciario de México en las repúblicas de Argentina y Brasil. ${ }^{59}$

1894 Es invitado a Nueva York por Federico Párraga (Colombiano) para integrarse al sindicatos de inventores (latinoamericanos). 1895 Crea la Sociedad Telegráfica y publica los Estatutos de la Sociedad Telegráfica Progresista. ${ }^{60}$

1896 Propone en el Congreso Postal la creación de una "Sociedad Internacional de amigos del progreso latinoamericano". Para defenderse de los abusos tarifarios y legales de la potencias de Europa y Estados Unidos.

1898 Primeras contrataciones de mujeres en México para desempeñarse como telegrafistas.

- Como resultado de los acuerdos del Congreso Postal, Nueva York transmitiría información meteorológica de México, misma que fue retransmitida al interior del país para el uso agrícola y naval.

- Se imparten cursos de física en los talleres de telegrafía, creando el concepto de oficina-escuela.

${ }^{58}$ Gabriel Jonas Lippmann (1845-1921) fue un físico luxemburgués y francés, galardonado con el Premio Nobel de Física en 1908 por su método de reproducción de los colores en fotografía, basado en el fenómeno de la interferencia. Su descubrimiento permite la reconstitución íntegra del conjunto de las longitudes de onda reflejadas por un objeto. Fue director del Laboratorio de Investigaciones Físicas; trabajó en muchos campos, como la electricidad, termodinámica, óptica y fotoquímica. En Heidelberg, estudió la relación existente entre los fenómenos eléctricos y capilares. Precisamente sobre este tema elaboró su tesis doctoral ("Relaciones entre los fenómenos eléctricos y capilares"). Estas investigaciones fueron la base necesaria para la construcción de un instrumento de precisión denominado electrómetro capilar.

${ }^{59}$ AP.PAV. ChPed,AM.892/05/06.IV-3. cont. [0511]

${ }^{60}$ AP.PAV. ChPed,AM.897/02/05.I-2. regl./telgr. [0586] 
- La revista Telegraph Age publicó el artículo "The Mexican Telegraphs", en donde da pormenores de los avances realizados durante la dirección de Chávez. ${ }^{61}$

1900 Se celebra en la casa de A. Comte, en París, una reunión de personas de diversas nacionalidades para intercambiar experiencias.

- Como Delegado de Caminos de Fierro viaja por varios países de Europa hacia Constantinopla; en el trayecto tiene oportunidad de disertar con varios socialistas perfeccionando sus ideas y concluyendo su ensayo de Economía política y filosófica.

- Concesión y Estatutos de la Compañía Proveedora de Agua, Alumbrado y Fuerza Motriz del Puerto de Alvarado. S.A. Lda. 1902 Vicepresidente del Círculo Progresista Alvaradeño. 
Anexo 2

"Estatutos de la Compañía Proveedora de Agua, Alumbrado y Fuerza Motriz del Puerto de Alvarado. S.A. Lda."

Las condiciones especiales de esta localidad tan favorecida por la naturaleza para hacer de ella una de las ciudades más bellas y prósperas de la República; su situación sobre la desembocadura de ríos navegables que recorren una de las regiones más ricas del país, y particularmente su gran salubridad, excepcional en todo el litoral del Golfo, son poderosos alicientes que hacen pensar desde luego en un gran porvenir para Alvardo y despiertan los más vivos deseos de contribuir al desenvolvimiento de se brillante porvenir, deseos tanto más justificados cuanto que quien actualmente los experimenta carecía del inestimable bien de la salud que aquí vino a encontrar.

Entre los elementos de prosperidad de Alvarado, hay dos muy importantes que no lo parecen y que son los vientos que reinan casi todo el año arriba de los médanos que protejen la ciudad al N. y al N.E., y la caudalosa corriente del río que se arrastra al pie de ellos.

De estas fuerzas se puede sacar gran partido, desde luego para proveer abundante de agua potable a la Ciudad con la presión que se quiera, así como de alumbrado eléctrico y fuerza motriz para usos domésticos e industriales.

Estos beneficios, repito, por las condiciones especiales de Alvarado, pueden disfrutarlos sus habitantes con gran ventaja y economía, y este es justamente el objeto de la presente solicitud que respetuosamente hago al $\mathrm{H}$. Consejo Municipal para que, si lo tiene a bien, me otorgue la concesión de los servicios publicos expresados: agua, alumbrado y fuerza motriz, bajo las bases que tengo la honra de someter a su ilustrado criterio y aprobación.

Antes de pasar a exponer esas bases, daré a conocer rápidamente mi proyecto.

Las fuerzas a que me he referido pueden recogerse fácilmente por medio de aero-motores y motores hidráulicos; al mismo tiempo pueden transformarse en electricidad por los procedimientos comunes y almacenar ese agente por medio de acumuladores eléctricos; y 
una vez almacenada la fuerza bajo la forma de electricidad, puede hacerse de ella lo que más convenga, esto es, tratándose de mi propósito, aplicarla a una bomba poderosa para elevar a lo alto de los médanos el agua potable que filtra al pie de ellos, dándoles así presión bastante para hacerla circular por las cañerías que previamente se instalarán en las calles y casas de la Ciudad. Y a la vez que este especie de sistema arterial, habrá otro de conductores llenos por donde circule la misma fuerza eléctrica y cuyas llaves servirán para encender lámparas, mover talleres, etc.

La gran economía que resulta del proyecto indicado está, jústamente, en que el viento y la corriente del río, lejos de constituir fuerzas como la del carbón, por ejemplo, que tiene un alto precio en el mercado, aún las brinda gratis la naturaleza a todo el que quiera, simplemente, tomarse el trabajo de hacer el gasto, muy pequeño relativamente, de instalar las máquinas o motores correspondientes.

Yo puedo disponer de motores perfeccionados de mucho mayor rendimiento y más prácticos y poderosos que los generalmente conocidos y cuya explotación, por sí sola, sería de benéficas consecuencias para el desarrollo ulterior de las riquezas naturales de Alvarado.

Podría objetarse que el aprovechamiento de las fuerzas naturales expresadas, aunque ventajoso, tiene el grave inconveniente de una variabilidad tal de intensidades, que aún llegan a sucederse días enteros de calmas en la época de fuertes calores, en que en vano se trataría de aprovechar la fuerza del viento, y la corriente misma del río es nula a las horas de cambio en las mareas. Pero todos estos inconvenientes están previstos al grado que, para completa seguridad del público, habrá además de las baterías refaccionarias de acumuladores requeridas, las instalaciones mismas de vapor hoy en uso, que estarán siempre a prevención y listas para funcionar cuando fuere necesario.

Mi iniciativa de concesión comprende, además, una parte en cierto modo inconexa con los asuntos a que me he referido, y la cual voy a explicar.

Inspirado en los patrióticos sentimientos de los alvaradeños y en los vehementes deseos que he podido observar en ellos de instruir a sus hijos, he creído que sería sin duda muy benéfico, a la vez que halagador, establecer el noble precedente de asociar a toda idea de lucro 
y provecho material, la muy levantada de la instrucción de la juventud, que es en mi concepto el mejor tributo que se puede pagar al verdadero progreso y bienestar de las generaciones futuras.

Tal es la razón de las cláusulas 22 a 29 del presente proyecto de Contrato que se refieren al establecimiento de las escuelas públicas de instrucción esencialmente laica, una para niños y otra para niñas y parvulitos.

Para concluir esta parte expositiva, réstame asegurar al $\mathrm{H}$. Consejo Municipal que si bien es cierto que hay motivos de interés personal que me mueven a hacer la presente solicitud, no son ellos los que me dominan sino de un verdadero altruismo y los del cariño y la gratitud. Alvarado, Marzo 30 de 1900.

A. M. Chávez.

\section{AL C. ALCALDE MUNICIPAL.- PRESENTE.}

\section{CONVOCATORIA}

a que se refiere el Acta de instalación de la Compañía.

Los que suscriben suplican a Ud. se sirva concurrir a la reunión que se celebrará en el Salón de Sesiones del Cabildo de esta Ciudad el día 17 del corriente a las 3:30 p.m. y que tendrá por objeto la organización de una Compañía Anónima Limitada para llevar a cabo la concesión que ha sido otorgada en debida forma al Sr. Ingeniero Don Agustín M. Chávez, para proveer de agua potable, alumbrado eléctrico y fuerza motriz al Puerto de Alvarado, y en cuya concesión y parte expositiva puede Ud. consultar en los ejemplares del "Boletín Municipal” que acompañan la presente invitación.

Alvarado, Mayo 16 de 1900.- Angel Tejeda.- Donacio Zamudio.Francisco S. Vives.- Zacarías Ramón.- Javier F. Zamudio.- José O. Aguirre.- Miguel Vives Santos.- A.M. Chávez.

Sr.

Presente. 
Anexo 3

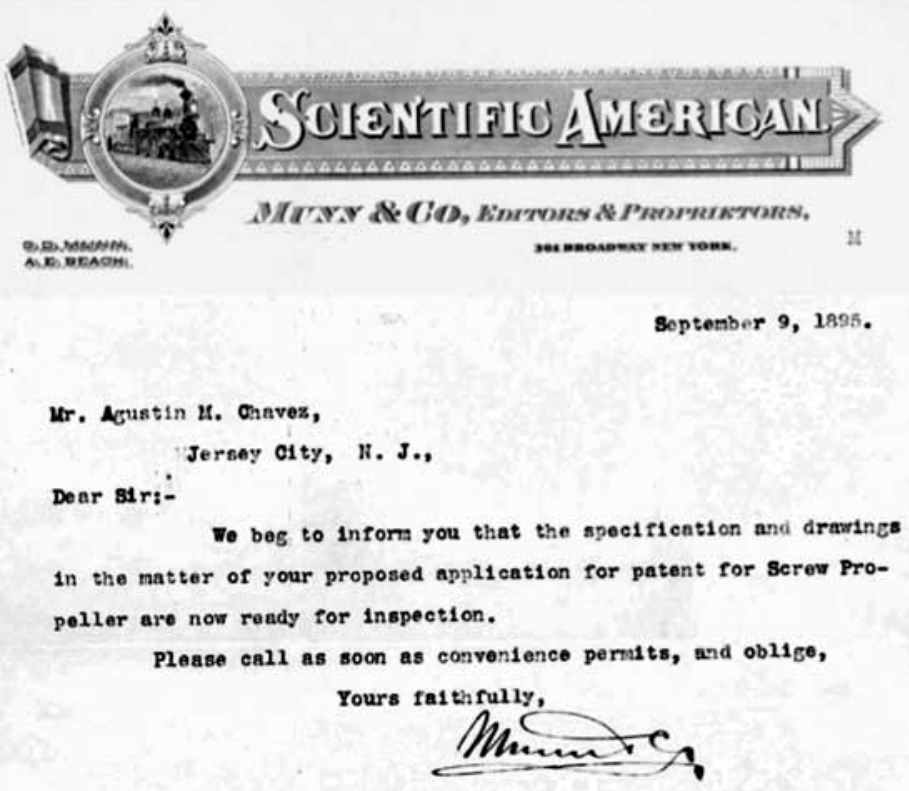

AP.PAV. ChPed,AM.895/09/09.I-2. corr/p. [0542]

Abreviaturas y BIbliografía

Fuentes

AP.PAV. Archivo Particular Pedro A. Velázquez

Personas

ChPed,AM. Chávez Pedroza, Agustín Manuel

Abreviaturas

$9_{\mathrm{m}}$ á $6_{\mathrm{t}}$ Nueve de la mañana a seis de la tarde AAFM-A.V. Compañía proveedora de Agua, Alumbrado y Fuerza Motriz del puerto de Alvarado, Veracruz. 
ane Anemodinámetro

ap/ane Apuntes sobre anemodinámetro

Ap/bio Apuntes de biología

ap/fis Apuntes de física

CA-P/889 Congreso de Aeronáutica de Paris, 1889

Car/Ms Carta Manuscrita

Corr/p Correspondencia para

nombto Nombramiento

publ.-ingl./telegr Publicación en inglés sobre telegrafía

$\mathrm{p}^{\mathrm{a}}, \mathrm{p}^{\mathrm{o}}, \mathrm{p}^{\mathrm{r}}, \mathrm{q}^{\mathrm{e}}$ para, pero, por, que

reg.pat. EU-P/890 Registro de patente-Exposición Universal de París, 1890

tes/ms Tesis manuscrita

[número] Número de legajo

Ejemplo de citas en fuentes de archivo particular:

\begin{tabular}{c|c|c|c|c|c|c} 
AP.PAV. & ChPed,AM. & $902 / 09 / 00$ & I & 2 & car/ms. & {$[0764]$} \\
\hline Colección & Persona & Año/mes/día & Archivero & Cajón & Tipo de Doc. & Legajo
\end{tabular}

\section{BiBLIOGRAFÍA}

Cabrera, Luis, "Dos opiniones sobre los cientificos", Historia de México, tomo 8, México, Ed. Salvat, 1974.

Concesión y Estatutos de la Compañia Proovedora de agua, alumbrado y Fuerza Motriz del Puerto de Alvarado S.A. Lda., México, Tip C. Lutteroth, 1900.

Garibay K., Ángel Ma., "Proemio", Diccionario Porrúa de historia, biografía y geografía de México, $3^{\text {a }}$ ed., tomo I, México, Ed. Porrúa, 1970.

GonzÁlez y González, Luis, La Ronda de las Generaciones. Los 
protagonistas de la Reforma y de la Revolución Mexicana, México, Sep, Cultura, Col. Foro 2000, 1984.

Guerra, François-Xavier, México: del Antiguo Régimen a la Revolución, sección Obras de historia, tomos I y II, 8 a Reimp., México, FCE, 2010.

Matute, Alvaro, "La educación pública", Historia de México, México, Ed. Salvat, tomo 9, 1974.

Londoño VegA, Patricia, "Cartillas y manuales de urbanidad y del buen tono. Catecismos cívicos y prácticos para un amable vivir", en Revista Credencial Historia, núm. 85, 1997.

Trabulse, Elías, Historia de la ciencia en México. Apéndices e indices, México, Col. Historia de la ciencia en México, FCE, 1984.

Velázquez, Pedro A., Amor, ciencia y gloria. La contribución de los Chávez y los Castañeda en el desarrollo del México moderno, Zamora, El Colegio de Michoacán, Col. Testimonios, 2001.

\section{FotografíA}

Fotografías digitalizadas de los originales que forman parte del Archivo Particular Pedro A.Velázquez.

\section{Hemeroteca}

Diario El Dictamen, México, noviembre de 1951. Archivo Particular Pedro A. Velázquez.

\section{INTERNET}

Herrera Feria, María de Lourdes, "Los actores locales de la modernidad a finales del siglo XIX: expositores poblanos en las exhibiciones mundiales", Nuevo Mundo Mundos Nuevos, Coloquios, 2009. http://nuevomundo.revues.org/index $55555 . \mathrm{html}$

FECHA DE RECEPCIÓN DEL ARTÍ́CUlO: 28 de agosto de 20 IO

FECHA DE ACEPTACIÓN Y RECEPCIÓN DE LA VERSIÓN FINAL: 29 de enero de 20 I I 